\title{
1 CURT1A and CURT1C mediate distinct stages of plastid conversion in Arabidopsis
}

3 Zizhen Liang ${ }^{\mathrm{a}}$, Wai Tsun Yeung ${ }^{\mathrm{a}}$, Keith Ka Ki Mai ${ }^{\mathrm{a}}$, Juncai Ma ${ }^{\mathrm{a}}$, Zhongyuan Liü, Yau-Lun Felix $4 \quad$ Chong $^{\mathrm{b}}$, Byung-Ho Kang ${ }^{\mathrm{a}}$

${ }^{a}$ Centre for Cell and Developmental Biology, State Key Laboratory for Agrobiotechnology, School of Life Sciences, The Chinese University of Hong Kong, Shatin, New Territories, Hong Kong, China bepartment of Physics, The Chinese University of Hong Kong, Shatin, New Territories, Hong Kong, 11

${ }^{1}$ These authors contributed equally to this work.

${ }^{2}$ Address correspondence to bkang@cuhk.edu.hk. The author responsible for distribution of materials integral to the findings presented in this article in accordance with the policy described in the Instructions for Authors (www.plantcell.org) is: Byung-Ho Kang (bkang@cuhk.edu.hk). 
bioRxiv preprint doi: https://doi.org/10.1101/2021.12.01.470752; this version posted December 1, 2021. The copyright holder for this preprint (which was not certified by peer review) is the author/funder. All rights reserved. No reuse allowed without permission.

62

\begin{abstract}
The crystalline structure of prolamellar bodies (PLBs) and light-induced etioplasts-to-chloroplasts transformation have been investigated with electron microscopy methods. However, these studies suffer from chemical fixation artifacts and limited volumes of tomographic reconstruction. We have examined Arabidopsis thaliana cotyledon samples preserved by high-pressure freezing with scanning transmission electron tomography to visualize larger volumes in etioplasts and their conversion into chloroplasts. PLB tubules were arranged in a zinc blende-type lattice like carbon atoms in diamonds. Within 2 hours after illumination, the lattice collapsed from the PLB exterior and the disorganized tubules merged to form fenestrated sheets that eventually matured into lamellar thylakoids. These planar thylakoids emerging from PLBs overlapped or folded into grana stacks in PLBs' vicinity. Since the nascent lamellae had curved membrane at their tips, we examined the localization of CURT1 proteins. CURT1A transcript was most abundant in de-etiolating cotyledon samples, and CURT1A concentrated at the peripheral PLB. In curt1a mutant etioplasts, thylakoid sheets were swollen and failed to develop stacks. In curt1c mutant, however, PLBs had cracks in their lattices, indicating that CURT1C contributes to cubic crystal growth under darkness. Our data provide evidence that CURT1A and CURT1C play distinct roles in the etioplast and chloroplast biogenesis.
\end{abstract}

\title{
Introduction
}

Plastids exist in different forms depending on the cell type and environmental conditions (Jarvis and López-Juez, 2013; Kirchhoff, 2019). In germinating seedlings, proplastids in the cotyledon develop into chloroplasts. As chlorophyll biosynthesis is inhibited under darkness, the photosynthetic protein complexes of the thylakoid membrane are not assembled, and chloroplast biogenesis is inhibited. Instead, developmentally plastids, known as etioplasts, form (Solymosi and Schoefs, 2010). The etioplasts transform into chloroplasts once light becomes available and chlorophyll accumulates (Hernandez-Verdeja et al., 2020).

Thylakoids in etioplasts consist of semi-crystalline tubular membrane networks of prolamellar bodies (PLBs) connected by planar prothylakoids (Ryberg and Sundqvist, 1982; Rascio et al., 1984). During the light-induced etioplast-chloroplast transition, the proteins, lipids, and cofactors stored in PLBs provide building blocks for the chloroplast thylakoids (Ploscher et al., 2011; Armarego-Marriott et al., 2019; Fujii et al., 2019). The most abundant protein constituent of PLBs is light-dependent protochlorophyllide oxidoreductase (LPOR) (Blomqvist et al., 2008), which forms a helical array surrounding PLB tubules (Floris and Kuhlbrandt, 2021). LPOR is a photocatalytic enzyme that mediates the reduction of protochlorophyllide (Pchlide) into chlorophyllide to produce chlorophyll (Zhang et al., 2019). LPOR oligomerize on liposomes mimicking the PLB membrane to tubulate them in vivo as shown by cryo-electron microscopy (Nguyen et al., 2021). It is thought that LPOR undergoes conformational changes after the photoreduction and dissociates from the PLB membrane, resulting in the breakdown of the PLB lattice. Inactivation of PORA, an Arabidopsis gene encoding an LPOR protein, led to structural defects in PLBs and abnormal photomorphogenesis (Paddock et al., 2012).

When examined under electron microscopy, PLBs are mostly made of hexagonal lattices in which tetrahedral units repeat (Murakami et al., 1985). Small angle X-ray studies of isolated PLBs revealed that branched tubules in PLBs are packed mostly in the cubic diamond (i.e., zinc blende) symmetry (Williams et al., 1998; Selstam et al., 2007). Recent electron tomography (ET) imaging of runner bean (Phaseolus coccineus) indicated that the PLB lattice matched the wurtzite-type crystal symmetry (Kowalewska et. al, 2016). PLBs in which tubules deviate from the tetrahedral pattern have been reported, and the arrangement is called the "open" type (Gunning, 2001). Moreover, etiolation conditions affect the sizes and density of PLBs (Bykowski et al., 2020).

The light-triggered transformation of PLBs into grana and stroma thylakoids was first investigated with electron microscopy in the 1960s, although those early studies were based on two-dimensional electron micrographs of PLBs and thylakoids (Gunning, 1965; Henningsen and Boynton, 1974; Rascio et al., 1984; Grzyb et al., 2013). An ET analysis of the etioplast-to-chloroplast transition in runner bean cotyledons showed that PLB tubules directly coalesce into planar thylakoid elements without involvement of vesicular intermediates and that the helical arrangement of the inter-disc connections within a grana stack appears early in the granum development (Kowalewska et al., 2016). In the Kowalewska study, the etioplast volumes in the ET reconstruction were limited in the z-direction 
bioRxiv preprint doi: https://doi.org/10.1101/2021.12.01.470752; this version posted December 1, 2021. The copyright holder for this preprint (which was not certified by peer review) is the author/funder. All rights reserved. No reuse allowed without permission.

coverage, visualizing two hexagonal layers in 3D. Using serial block face-scanning electron microscopy, it was demonstrated that the conversion of PLBs into photosynthetic thylakoids in Arabidopsis cotyledons is within 24 hour after light illumination in concurrence with correlative proteomic and lipidomic results (Pipitone et al., 2021). The serial block face-scanning electron microscopy approach can visualize larger volumes encompassing the entire etioplasts or chloroplasts, but the resolution is poorer than ET, especially along the z-axis. In both 3D EM studies, cotyledon samples were prepared with chemical fixation, which fails to preserve intricate or short-lived structures in cells (Mclntosh et al., 2005; Staehelin and Kang, 2008).

In this study, we examined etioplasts in Arabidopsis cotyledons grown in the dark with serial section ET. Cotyledon samples were prepared by high-pressure freezing to avoid fixation artifacts. As the stroma is heavily stained in high-pressure frozen etioplasts, we employed scanning transmission ET (STET), which enhances image contrast in tomograms from such specimens (Aoyama et al., 2008; Hohmann-Marriott et al., 2009; Murata et al., 2014; Kang, 2016). CURVATURE THYLAKOID1 (CURT1) family proteins are thylakoid membrane proteins that stabilize the sharply curved membrane at the grana margin (Armbruster et al., 2013; Pribil et al., 2014). Our time-resolved ET study of wildtype and curt 1 family mutant cotyledons indicated that grana stacks arise directly from PLBs and that CURT1A is required for the stack assembly. By contrast, CURT1C plays a role in the cubic crystal close packing for PLB biogenesis in developing etioplasts.

\section{Results \\ Crystalline structure of the Arabidopsis PLBs and their light-induced degradation}

To estimate the timeline of the etioplast-to-chloroplast transformation, we examined etiolated Col-0 Arabidopsis cotyledons at 0,2, 4, 8, and 12 hours after light illumination (HAL). Cotyledon greening was clearly observed at $12 \mathrm{HAL}$ (Fig. 1A-C), and chlorophyll autofluorescence increased during this period (Fig. S1A-E). PLBs were small spots of 1.5-2.0 $\mu \mathrm{m}$ in diameter that emitted autofluorescence in 0 HAL cotyledons (Fig. 1D). The fluorescent spots were enlarged and spread out to form ovals at 2 HAL (Fig. 1E). We monitored the degradation of PLBs with transmission electron microscopy (TEM) and STET at the five time points. Each etioplast had one or two PLBs that were linked by multiple lamellar thylakoids at $0 \mathrm{HAL}$ (Fig. $1 \mathrm{~F}$ and S1F). Lamellar thylakoids in $0 \mathrm{HAL}$ etioplasts were ribosomes on their membranes, like the pre-granal thylakoids in proplastids of germinating cotyledon cells at 36 and 64 hours after imbibition reported in Liang et al. (2018).

PLBs shrank quickly and lost their crystalline regularity by $2 \mathrm{HAL}$ (Fig. 1G-H and S1G). Grana stacks of two layers appeared in the vicinity of PLB as early as $1 \mathrm{HAL}$ (Fig. 1G), and the number of disks had increased in the PLB-associated grana stacks at $2 \mathrm{HAL}$ (Fig. 1H). PLBs were almost degraded at 4 $\mathrm{HAL}$ and had disappeared completely in $8 \mathrm{HAL}$ samples (Fig. 1I-J and S1H-I). Grana stacks and stroma thylakoids were evident in cotyledon cells at $12 \mathrm{HAL}$, and the chloroplasts had starch particles (Fig. $1 \mathrm{~K}$ and S1J). Chloroplasts at $12 \mathrm{HAL}$ were approximately $25 \%$ larger than etioplasts at $0 \mathrm{HAL}$ (Fig. S1K).

Loss of the crystalline architecture began at the PLB surface (Fig. 1G). During the loss of the crystalline architecture, the inner core retained the lattice structure, and tubules in the periphery were highly convoluted (Fig. 1G). In between the crystalline core and the irregular periphery was a narrow band in which the lattice arrangement was compromised (Fig. 1G). No crystalline symmetry was discerned in PLBs at $2 \mathrm{HAL}$, but grana stacks were detected at the PLB surface (Fig. 1H), suggesting that grana-forming super-complexes containing LHCII are assembled where chlorophyll molecules are produced from protochlorophyllides in the PLB.

We generated 3D surface models of PLB tubules in the periphery of PLBs and in the intermediate zone of PLBs from 0 and $1 \mathrm{HAL}$ images. PLBs before illumination consisted of tetravalent nodes (Fig. $1 \mathrm{~L})$, and the average width of the tubules was calculated to be $24.0 \mathrm{~nm}(\mathrm{n}=46, \mathrm{SD}=3.11)$. In the intermediate zone at $1 \mathrm{HAL}$, tubular nodes were displaced, obscuring the hexagonal pattern (Fig. 1M). The peripheral tubules were highly disordered and had varying thicknesses (Fig. $1 \mathrm{~N}$ ).

\section{Skeleton models of PLBs}

We converted PLBs in our tomograms into 3D skeleton models consisting of lines and nodes using the MATLAB software package (Fig. S2). Hexagonal and square lattices were discerned in the $0 \mathrm{HAL}$ 
bioRxiv preprint doi: https://doi.org/10.1101/2021.12.01.470752; this version posted December 1, 2021. The copyright holder for this preprint (which was not certified by peer review) is the author/funder. All rights reserved. No reuse allowed without permission.

140

141

142

143

144

145

146

147

148

149

150

151

152

153

154

155

156

157

158

159

160

161

162

163

164

165

166

167

168

169

170

171

172

173

174

175

176

177

178

179

180

181

182

183

184

185

186

187

188

189

190

191

192

193

194

195

196

197

198

199

skeleton model (Fig. 2A-B). Among crystallographic symmetries associated with PLBs, the diamond cubic symmetry matched our PLB skeleton model. We were able to capture views of the models corresponding to the Miller index planes of the diamond cubic symmetry (Fig. 2C-E). The hexagonal periodic patterns conformed to the $(1,1,1)$ or $(1,1,0)$ planes, whereas the square lattice matched the $(1,0,0)$ plane. The diamond cubic unit cell size averaged to $65.5 \mathrm{~nm}(\mathrm{n}=61, \mathrm{SD}=3.71)$ when measured from nodes in the $(1,1,0)$ or $(1,0,0)$ planes.

From the skeleton models from 1, 2, and 4 HAL PLBs (Fig. 2F-H), we calculated radial densities of nodes and branching numbers per node at each time point. The node density plot had a peak from 30 $\mathrm{nm}$ to $70 \mathrm{~nm}$ in $0 \mathrm{HAL}$ and $1 \mathrm{HAL}$ crystalline PLBs, indicating a regular spacing between nodes (Fig. 21). The peak was not present in irregular region of PLBs at $1 \mathrm{HAL}$. In agreement with the tetravalent units seen in 3D models (Fig. 1M), each node had four branches in $0 \mathrm{HAL}$ and $1 \mathrm{HAL}$ crystalline PLBs (Fig. 2J). Numbers of branches decreased as PLBs were degraded in later time points (Fig. 2K) and the reduction was accompanied by an increase in tubule thickness (Fig. 2L).

\section{Assembly of lamellar thylakoids and grana stacks on the PLB surface}

3D tomographic models of the PLB-thylakoid interface at 1,2, and $4 \mathrm{HAL}$ were generated to examine how PLB tubules give rise to pre-granal thylakoids and how they turn into grana stacks. The irregular tubules observed in the PLB periphery at $1 \mathrm{HAL}$ became interwoven and smoothened to constitute fenestrated membrane sheets at later time points. They consolidated into pre-granal thylakoids as their openings shrank and disappeared (Fig. 3A-C). Thylakoids in the immediate vicinity of PLBs were fenestrated at $2 \mathrm{HAL}$, indicating that PLB tubules continued to fuse (Fig. 3D-E).

Stacked thylakoids appeared on the PLB surface at 2 HAL where two pre-granal thylakoids were laterally fastened to each other or grana-forming buds emerged (Fig. 3F-G). Three or four-layered grana were also observed when thylakoid sheets overlap or fold repeatedly. The acquisition of new layers did not seem to occur in an orderly fashion (Fig. $3 \mathrm{H}-\mathrm{I}$ ). Their diverse membrane configurations were similar to those of pro-granal stacks in young chloroplasts of germinating cotyledon cells (Liang et al. 2018). Grana stacks displaced from PLBs were frequently observed at 4 HAL (Fig. 3G-H). They had five or six disks interconnected by helical stroma thylakoids as typical grana stacks do.

To correlate expression levels of thylakoid membrane proteins with thylakoid assembly, we performed RNA-seq analysis of de-etiolating cotyledon samples isolated at $0,1,2,4,8$, and 12 HAL. Most components of the photosystems and light harvesting complexes were upregulated at $2 \mathrm{HAL}$ when grana stacks appeared on the PLB surface (Fig. S3A). Levels of Lhcb, which encodes a protein necessary for thylakoid stacking, sharply increased between $1 \mathrm{HAL}$ and $2 \mathrm{HAL}$ (Fig. S3B). The mRNAs encoding PSII components and LHCB were generally more abundant than mRNAs encoding PSI constituents and LHCA before 2 HAL.

\section{CURT1A localizes to the nascent pre-granal thylakoids emerging from PLBs and grana stacks}

Pre-granal thylakoids and grana stacks emerging from the PLB surface had membranes sharply curved membrane toward the stroma (Fig. 3). This led us to hypothesize that CURT1 family proteins, which stabilize the grana margin, are involved in stack assembly from PLB tubules (Armbruster et al., 2013; Pribil et al., 2014). Among the four CURT1 family genes, curt1a (AT4G01150) were more abundant than other members of the family in de-etiolating Arabidopsis cotyledons (Fig. S3C). We generated transgenic Arabidopsis lines expressing a CURT1A-GFP fusion protein under control of its native promoter to monitor its localization during de-etiolation. The fusion protein construct rescued the granum assembly defects of curt1a-1 mutant cotyledons, indicating that the fusion protein is functional (Fig. S4 and S5). At 0 HAL, GFP fluorescence colocalized with PLB autofluorescence, although this colocalization was not complete; some PLBs had a GFP halo or GFP-positive puncta around them (Fig. 4A). In 2 and 4 HAL cells, PLB became smaller and chlorophyll autofluorescence spread over de-etiolating chloroplasts, and CURT1A-GFP formed foci on PLBs in 2 HAL chloroplasts (Fig. 4B). As thylakoids permeated the stroma, small GFP spots scattered to multiple locations in 4 HAL chloroplasts (Fig. 4C). CURT1A-GFP at 4 and 8 HAL were round or rod-shaped (Fig. 4D). We verified the association of CURT1A with PLBs with immunogold labeling. CURT1A-specific gold particles associated most frequently with the PLB surface where new thylakoid elements arise at 0 and $2 \mathrm{HAL}$ (Fig. 4E-G and J). As PLBs were being consumed at 4 and $8 \mathrm{HAL}$, the majority of CURT1A relocated to thylakoids, binding to grana stacks in the stroma (Fig. $4 \mathrm{H}-\mathrm{L}$ and J).

\section{Assembly of pre-granal thylakoids and grana stacks is abnormal in curt1a mutant cotyledons}


bioRxiv preprint doi: https://doi.org/10.1101/2021.12.01.470752; this version posted December 1, 2021. The copyright holder for this preprint (which was not certified by peer review) is the author/funder. All rights reserved. No reuse allowed without permission.

To test whether CURT1A is required for the pre-granal thylakoid assembly and grana formation, we isolated curt1a T-DNA inserted mutant lines (Fig. S4 and S5). Etioplasts in 0 HAL curt1a-1 (SALK_030000) cotyledons appeared normal. However, at 1 HAL, thylakoids on the PLB surface were swollen in mutant cotyledon cells in contrast to the flat pre-granal thylakoids in wild-type cotyledon cells (Fig. 5A-B). The bloated thylakoids failed form grana stacks. Instead, round thylakoids accumulated around PLBs at 2 and 4 HAL in the mutant (Fig. 5C-D). Despite the lack of grana stack formation, PLBs shrank and stroma thylakoids continued to expand (Fig. 5E). Chloroplasts had extremely extended stacks made of two or three layers in curt1a-1 mutant cotyledon cells at $12 \mathrm{HAL}$ (Fig. 5F). Another T-DNA mutant allele of curt1a (curt1a-2, GK-805B04) also had swollen thylakoids and lacked grana stacks, and the phenotype was rescued upon transformation with the CURT1A-GFP construct (Fig. S5G-K).

The cubic crystalline lattice is interrupted in curt1c mutant PLBs

As transcripts from curt1b (AT2G46820) and curt1c (AT1G52220) accumulated in de-etiolating cotyledon cells, we examined T-DNA mutant lines in which curt1b or curt1c was inactivated (Figs. 6 and S6). We noticed that PLBs of curt1C-1 (SALK_023574) cotyledons often had irregularities (Fig. 6 $\mathrm{A}, \mathrm{B}$, and J). Pores as large as $400 \mathrm{~nm}$ (Fig. 6A) or areas where PLB tubules were disorganized (Fig. $6 B$ ) were seen curt1c-1 PLBs. However, they did not have swollen thylakoids around PLBs and grana stacks developed in association with degrading PLBs at 4 HAL (Fig. 6D-E). When we expressed CURT1C-GFP from its native promoter in the curt1c-1 background, the defects in PLBs disappeared (Fig. 6C and J).

CURT1C-GFP expressed by the CURT1C promoter overlapped almost completely with PLB autofluorescence at $0 \mathrm{HAL}$ and shrank together with PLBs (Fig. 6E-F). This contrasted with CURT1AGFP which enclosed PLBs or constituted foci around PLBs (Fig. 6G-H). In 4 HAL plastids where PLBs have been mostly depleted, GFP-positive spots were scattered over thylakoids in a manner similar to that of CURT1A-GFP (Fig. 6I). PLBs, their degradation, and thylakoid development around PBLs appeared normal in curt1b-1 (WiscDsLoxHs047_09D) cotyledon cells (Figs. S6). However, in all alleles of curt1a, 1b, and 1c, grana stacks had fewer layers and were wider than those in wild-type chloroplasts at $12 \mathrm{HAL}$ (Figs. 1, 5, 6, and S6). 
bioRxiv preprint doi: https://doi.org/10.1101/2021.12.01.470752; this version posted December 1, 2021. The copyright holder for this preprint (which was not certified by peer review) is the author/funder. All rights reserved. No reuse allowed without permission.

\section{Discussion}

We have determined the crystalline structure of Arabidopsis PLBs in high-pressure frozen etioplast samples to be zinc blende type. This result agrees with a small angle X-ray diffraction study of isolated maize PLBs (Selstam et al., 2007). We did not find any evidence in our 3D models for wurtzite-type lattices; this lattice was detected in runner bean by Kowalewska et al. (2016). The wurtzite lattice was seen at the boundary between zinc blende crystal domains in squash etioplasts (Murakami et al., 1985). The zinc blende lattice is a center-closest packed crystal system with a repeating unit of three layers, whereas the wurtzite lattice is a hexagonal closest packed system with a repeating unit of two layers (Cotton et al., 1995). We prepared approximately $300-\mathrm{nm}$ thick sections that enclose more than four layers within PLBs and examined them with STET. Due to the dark staining of stroma in cryofixed samples, it was impossible to acquire tomograms in the brightfield mode with signal-to-noise levels sufficient for automatic segmentation. It was crucial to employ STET to enhance the membrane contrast in order to establish the crystalline structure of PLBs.

The LPOR-Pchlide-NADPH ternary complex binds to the lipid bilayer to produce membrane tubules in vitro, and the complex breaks apart upon illumination to release raw materials necessary for constructing photosynthetic thylakoids (Nguyen et al., 2021). We observed collapse of crystalline order from the peripheral PLBs at $1 \mathrm{HAL}$, indicating that light activation of LPOR and subsequent Pchilde reduction began from the PLB exterior. The loss of crystalline architecture at $1 \mathrm{HAL}$ was characterized by randomized internodal distances, reduced branching per nodes, and thickening of tubules. The tetrahedral branching points were dislocated in the intermediate zone in $1 \mathrm{HAL}$ PLBs. Lying between the inner crystalline and outer irregular regions, the intermediate zone is likely the site of PLB lattices in which LPOR-Pchlide-NADPH ternary complexes have disassembled immediately after illumination.

One of the first events in the conversion of proplastids into chloroplasts is the formation of pregranal thylakoids from tubule-vesicular prothylakoids (Liang et al., 2018). Our data indicate that at the PLB-stroma interface, pre-granal thylakoids develop from PLB tubules, and grana stacks arise from the pre-granal thylakoids (Fig. 7A). Localization of CURT1A, CURT1A-GFP, and curt1a mutant phenotypes provided evidence that CURT1A stabilize the curve membrane at the tip of pre-granal thylakoid emerging from PLBs. In curt1a mutant lines, we observed swollen thylakoids in association with degrading PLBs (Fig 7B). CURT1A-GFP complemented the curt1a phenotype, and the fusion protein localized to the PLB margin. We hypothesize that the sites in PLBs where CURT1A-GFP concentrated at 0 and 2 HAL correspond to sites from which new pre-granal thylakoids and grana stacks develop. No grana stacks developed in the vicinities of PLBs in curt1a mutants in agreement with the observed recruitment of CURT1A to the PLB periphery. All three curt 1 isotypes, $1 a, 1 b$, and 1c, were transcriptionally active, and their gene products were detected in de-etiolating cotyledon specimens. The curt $1 \mathrm{~b}$ and curt1c mutant lines did not exhibit defects in the transition of PLBs into pre-granal thylakoids.

The morphological gradient from tubules into fenestrated sheets, and further into mature pregranal thylakoids (Fig. 7C) is reminiscent of cell plate maturation (Otegui et al., 2001; Otegui and Staehelin, 2004; Segui-Simarro et al., 2004). Vesicle fusion at the cell plate produces tubules that merge with each other to form fenestrated sheets. As the cell plate expands and matures, fenestrated sheets are consolidated into a new cell boundary (Samuels et al., 1995; Kang et al., 2003; Ahn et al., 2017). The membrane dynamics from tubules to planar thylakoids is completed in a miniature scale within several hundred nanometers from the PLB. However, the pre-granal thylakoid formation we observed was oriented backward from the cell plate assembly. Unlike the cell plate where vesicles and tubules are recruited to the growing end, sheet-like thylakoids outgrow from PLBs into the stroma.

PLBs in curt $1 \mathrm{c}$ mutant cotyledons had large holes or disarrayed tubules, indicating that CURT1C is required for PLB assembly in darkness. When we expressed CURT1C-GFP from the native curt 1c promoter, the defects were rescued, indicating a skotomorphogenic function of CURT1C (Fig. 7D). During de-etiolation, CURT1C-GFP spread uniformly over PLBs, and the signal faded 
bioRxiv preprint doi: https://doi.org/10.1101/2021.12.01.470752; this version posted December 1, 2021. The copyright holder for this preprint (which was not certified by peer review) is the author/funder. All rights reserved. No reuse allowed without permission.

289 together with PLB degradation. This GFP localization contrasted with that of CURT1A-GFP. The distinct phenotypes of curt1a and curt1c suggest that CURT1A selectively interacts with the machinery in the PLB periphery producing pre-granal thylakoids and grana stacks. It will require 3D electron microscopic analyses of etiolating plastids at multiple time points after seedling germination under darkness to characterize functions of CURT1C in PLB biogenesis.

In a recent publication, it was reported that chloroplast biogenesis from etioplasts and the PLB structure are affected in the curt1abcd quadruple mutant seedlings and that overexpression of CURT1A altered PLB morphology (Sandoval-lbanez et al., 2021). We discovered that CURT1A and CURT1C contribute to the PLB-to-pre-granal thylakoid transformation and the development of semi-crystalline structure of PLBs, respectively. We were not able to confirm changes in PLBs after CURT1A overexpression as our CURT1A-GFP was expressed from the endogenous curt1a promoter. The defects we observed in curt1a and $1 c$ mutant lines are not in agreement with the observations documented by Sandoval-Ibanez et al. (2021) probably because curt1abcd specimens were processed by traditional protocols that involve fixation and dehydration at room temperature. It is generally accepted that membranous structures, including thylakoids, are preserved closer to their native states by cryofixation than by conventional fixation (Kiss et al., 1990; Kang, 2010; Nicolas et al., 2018; Otegui, 2021). Functional characterization of a plastidtargeted protein, FZL, provides an example. Inhibition of thylakoid membrane fusion in $\mathrm{fz} /$ mutant chloroplasts was discerned in high-pressure frozen samples (Liang et al., 2018) but not in chemically fixed samples in an earlier study (Gao et al., 2006). 
bioRxiv preprint doi: https://doi.org/10.1101/2021.12.01.470752; this version posted December 1, 2021. The copyright holder for this preprint (which was not certified by peer review) is the author/funder. All rights reserved. No reuse allowed without permission.

311

312

313

314

315

316

317

318

319

320

321

322

323

324

325

326

327

328

329

330

331

332

333

334

335

336

337

338

339

340

341

342

343

344

345

346

347

348

349

350

351

352

353

354

355

356

357

358

359

360

361

362

363

364

365

366

367

368

369

370

\section{Methods \\ Plant Materials and Growth Conditions}

Arabidopsis Columbia (Col-0) and curt1 seeds (NASC, http://arabidopsis.info/) were surface-sterilized and incubated in $4^{\circ} \mathrm{C}$ overnight. The seeds then were placed on $0.75 \%$ phytoagar Petri dishes supplemented with half-strength Murashige-Skoog salt (0.5 g/L, pH 5.8). The dishes were placed in a growth chamber (Cat No. MLR-352H-PB, Panasonic, Japan) at $22^{\circ} \mathrm{C}$ and were left to germinate and grow for 1 week under darkness. Samples were harvested after illumination with white fluorescent light at a photon flux intensity of $120 \mu \mathrm{mol} \mathrm{m}^{-2} \mathrm{~s}^{-}$before dissection. The isolated cotyledon samples were analyzed by high-pressure freezing, RNA-seq, or confocal laser scanning microscopy.

\section{Chlorophyll extraction and measurement}

Chlorophyll extraction and measurement were performed as described by Ma et al. (Ma et al., 2021). Arabidopsis seedlings were before incubated in $700 \mu \mathrm{L}$ pre-heated DMSO in $65^{\circ} \mathrm{C}$ for 30 minutes and ground for centrifugation at $6000 \mathrm{rpm}$ for 10 minutes. Another $300 \mu \mathrm{L}$ pre-heated DMSO were added to the supernatant to make the final volume of $1 \mathrm{~mL}$. The OD at $645 \mathrm{~nm}$ and $663 \mathrm{~nm}$ for chlorophyll a and chlorophyll b were measured with NanoDrop (Thermofisher). The Chlorophyll concentration was calculated with the Arnon's equations. The experiment was repeated for three times and the quantification of chlorophyll concentration was performed using Microsoft Excel 2016, the graphs were made by Prism8 (GraphPad Software).

\section{Generation of CURT1A-GFP, CURT1C-GFP lines in their respective mutant backgrounds}

The genomic fragment of CURT1A (AT4G01150) and CURT1C (AT1G52220) including $\sim 2 \mathrm{~kb}$ promoter region was amplified and inserted into a binary vector pBI121. The last exons of the genes were translationally fused with the GFP in the vector. curt1a-1 and curt1c-1 plants were transformed with the CURT1A-GFP and CURT1C-GFP constructs, respectively by floral dip method with the Agrobacterium tumefaciens strain GV3101(Zhang et al., 2006). Transgenic seedling (T1) were selected by kanamycin containing $1 / 2 \mathrm{MS}+0.8 \%$ agar $(\mathrm{w} / \mathrm{v})$. Seedlings (T2 generation) were tested for GFP expression with immunoblot analysis (anti-GFP antibody, 1:2500 dilution, Abcam Cat\# av290) and observed under Leica TCS SP8 Confocal Microscope System. All the primers were from Integrated DNA Technologies, and the genomic fragments were amplified with iProof high-fidelity DNA polymerase (Bio-Rad). The primer sequences for the GFP cloning are in Supplemental Table 2.

\section{High-pressure freezing (HPF), sample processing, and TEM}

High-pressure freezing, freeze substitution, resin embedding, and ultramicrotomy were performed as described in Kang (Kang, 2010). Seedlings were examined with a Canon EOS M50 Digital Camera equipped with fluorescence illumination to remove abnormal cotyledons before freezing. Frozen samples were freeze-substituted in anhydrous acetone with $1 \% \mathrm{OsO} 4$ at $-80^{\circ} \mathrm{C}$ for $24 \mathrm{hr}$. Excess $\mathrm{OsO} 4$ was removed at $-80^{\circ} \mathrm{C}$ by rinsing with precooled acetone. After being slowly warmed up to room temperature over $60 \mathrm{~h}$, samples were separated from planchettes and embedded in Embed-812 resin (Electron Microscopy Sciences; catalog no. 14120). $80 \mathrm{~nm}$ thick sections of each time point were prepared with ultramicrotomy and then were examined with a Hitachi 7400 TEM (Hitachi-High Technologies) operated at $80 \mathrm{kV}$.

Dual-axis scanning Transmission Electron Tomography (STEM), Tomogram Reconstruction, Modeling, and Measuring Morphometric Parameters

$300 \mathrm{~nm}$ thick sections were collected on formvar-coated copper slot grids (Electron Microscopy Sciences; catalog no. GS2010-Cu) and stained with $2 \%$ uranyl acetate in $70 \%$ methanol followed by Reynold's lead citrate (Mai et al., 2019). Tilt series from $\pm 54^{\circ}$ at $1.5^{\circ}$ intervals in scanning transmission electron microscopy (STEM) mode were collected with a 200-kV Tecnai F20 intermediate voltage electron microscopy (Thermo-Fischer, USA). FEI STEM Tomography interface was used to collect two tilt series around the orthogonal axe as described in Kang (2016) and membrane surface models were prepared according to (Mai and Kang, 2017).

\section{Immunoblot Analysis and Immunogold Labeling}

Protein samples were extracted from seedlings at $0 \mathrm{~h}, 1 \mathrm{~h}, 2 \mathrm{~h}, 4 \mathrm{~h}, 8 \mathrm{~h}$ and $12 \mathrm{~h}$ of light treatment after being pulverized in liquid nitrogen. SDS-PAGE and immunoblot were performed as described by Liang et al. (2018) and Lee et al. (Lee et al., 2013). The experiment was repeated for three times with total protein extracts from three independent sets of cotyledon samples. For immunogold labeling, thin sections ( $80 \mathrm{~nm}$ thick) of HM20 embedded samples at each time point were prepared by 
bioRxiv preprint doi: https://doi.org/10.1101/2021.12.01.470752; this version posted December 1, 2021. The copyright holder for this preprint (which was not certified by peer review) is the author/funder. All rights reserved. No reuse allowed without permission.

ultramicrotomy, the following immunodetection of gold particles were performed according to the protocol explained in Wang et al. (Wang et al., 2017). Antibodies for CURT1A (AS08 316), CURT1B (AS19 4289), CURT1C (AS19 4287) and PORA (AS05 067) were purchased from Agrisera. AntiPBA1 antibody (ab98861) was purchased from Abcam.

\section{Transcriptomic Analyses}

RNA samples were isolated from seedlings at each time point with 3 biological replicates using Qiagen Plant RNA extraction kit (Qiagen; catalog no. 74904). A total of $18 \mathrm{cDNA}$ libraries were prepared following the standard BGISEQ-500 RNA sample preparation protocol and sequenced by the DNBseq platform (BGI, Shenzhen, China). Raw reads were filtered by SOAPnuke software, about $23.23 \mathrm{~m}$ clean reads for each sample were obtained in FASTQ format. The transcript expression level was then calculated and normalized to FPKM using RSEM software. The heat maps and the line charts were generated with $R$ Studio (version 1.1.383) as described previously (Liang et al., 2018). FPKM values for CURT1 family genes and Lhcb were calculated to evaluate their expression level.

Generation of skeleton models from PLB tubules

PLB membranes were first segmented using the 3D Orientation Field Transform tool (https://arxiv.org/abs/2010.01453). Skeletons were generated from the segmented membrane tubules by performing a medial axis transform (also known as 'skeletonisation') with an in-built MATLAB algorithm. Each skeleton element was converted into an undirected adjacency matrix carrying node coordinates using the Skel2Graph3D algorithm developed by (Kollmannsberger et al., 2017). The Bresenham's line algorithm was used to connect node pairs with a straight line (https://arxiv.org/abs/2010.01453). The MATLAB adaptation of the Bresenham's line algorithm iptui.intline() was modified for the purpose.

\section{Analysis of computer generated PLB skeleton models.}

The radial distribution function was computed by first plotting a histogram of the distances $r$ between all the nodes in the skeleton, then the binned number was divided by $4 \pi r^{2}$. A curve approximating the histogram was used to generate probability plots against radial distances. Numbers of branches were counted from skeleton models at each time points. A distance transform with an in-built MATLAB algorithm was used on the binary segmented PLB tomograms to estimate PLB tubule thicknesses. The skeleton of the original segmentation was then introduced as a mask to select voxels around the central axes of PLB tubules. Approximate radii of PLB tubules were calculated from sizes of the voxels. The radii values were doubled to acquire diameters that correspond to tubular thicknesses. As we have calculated diameters from numerous voxels along auto-segmented PLB tubules, we were able to acquire low p-values (high degrees of confidence) in the pairwise comparisons. 
bioRxiv preprint doi: https://doi.org/10.1101/2021.12.01.470752; this version posted December 1, 2021. The copyright holder for this preprint (which was not certified by peer review) is the author/funder. All rights reserved. No reuse allowed without permission.

\section{Accession Numbers}

410 The RNA-seq data have been deposited in NCBI Sequence Read Archive under accession number 411 GSE189497.

\section{Supplemental Data}

414 The following material is available in the online version of this article.

415 Supplemental Figure 1. Etioplast-chloroplast transition in de-etiolating Arabidopsis cotyledons

416 Supplemental Figure 2. Generating skeleton models from PLB tubules in tomograms.

417 Supplemental Figure 3. Analyses of transcripts in de-etiolating Arabidopsis cotyledons that encode

418 proteins associated with photosynthesis.

419 Supplemental Figure 4. Characterization of curt1 T-DNA inserted mutant lines.

420 Supplemental Figure 5. The abnormal thylakoid assembly phenotype reproduced in the curt1a-2 (GK805B04) allele and rescue of curt1a defects by expression of CURT1A-GFP

Supplemental Figure 6. Etioplast-to-chloroplast differentiation in curt 1b-1 cotyledons.

Supplemental Table 1. Statistics of the three rounds of RNA-seq experiments at the six time points. Supplemental Table 2. Primer sequences for genotyping or molecular cloning

Supplemental dataset 1. The skeletal model file of a PLB shown in Figure 3.

\section{Acknowledgements}

This work was supported by the Hong Kong Research Grant Council (GRF14121019, 14113921, AoE/M-05/12, C4002-17G) and Chinese University of Hong Kong (Direct Grants).

431

\section{Author Contributions}

B-H. K. and Z.L. designed the research. Z.L., W.T.Y., K.K.M., J.M. Z.L. and Y-L. F. C. performed the experiments. All authors analyzed the data. B-H. K. and Z.L. wrote the article.

435

436

437

\section{Competing Financial Interest Statement}

438

The authors declare no competing financial interest.

439

440

441 
bioRxiv preprint doi: https://doi.org/10.1101/2021.12.01.470752; this version posted December 1 , 2021. The copyright holder for this preprint (which was not certified by peer review) is the author/funder. All rights reserved. No reuse allowed without permission.

442

443

444

445

446

447

448

449

450

451

452

453

454

455

456

457

458

459

460

461

462

463

464

465

466

467

468

469

470

471

472

473

474

475

476

477

478

479

480

481

482

483

484

485

486

487

488

489

490

491

492

493

494

495

496

497

498

499

500

\section{References}

Ahn, G., Kim, H., Kim, D.H., Hanh, N.H., Yoon, Y., Singaram, I., Wijesinghe, K.J., Johnson, K.A., Zhuang, X.-H., Liang, Z., Stahelin, R.V., Jiang, L., Cho, W., Kang, B.-H., and Hwang, I. (2017). SH3P2 plays a crucial role at the step of membrane tubulation during cell plate formation in plants. THE PLANT CELL ONLINE 29, 1388 - 1405.

Aoyama, K., Takagi, T., Hirase, A., and Miyazawa, A. (2008). STEM tomography for thick biological specimens. Ultramicroscopy 109, 70-80.

Armarego-Marriott, T., Kowalewska, L., Burgos, A., Fischer, A., Thiele, W., Erban, A., Strand, D., Kahlau, S., Hertle, A., Kopka, J., Walther, D., Reich, Z., Schottler, M.A., and Bock, R. (2019). Highly Resolved Systems Biology to Dissect the Etioplast-to-Chloroplast Transition in Tobacco Leaves. Plant Physiol 180, 654-681.

Armbruster, U., Labs, M., Pribil, M., Viola, S., Xu, W., Scharfenberg, M., Hertle, A.P., Rojahn, U., Jensen, P.E., Rappaport, F., Joliot, P., Dörmann, P., Wanner, G., and Leister, D. (2013). Arabidopsis CURVATURE THYLAKOID1 proteins modify thylakoid architecture by inducing membrane curvature. THE PLANT CELL ONLINE 25, 2661 - 2678.

Blomqvist, L.A., Ryberg, M., and Sundqvist, C. (2008). Proteomic analysis of highly purified prolamellar bodies reveals their significance in chloroplast development. Photosynthesis Research 96, 37-50.

Bykowski, M., Mazur, R., Buszewicz, D., Szach, J., Mostowska, A., and Kowalewska, L. (2020). Spatial Nano-Morphology of the Prolamellar Body in Etiolated Arabidopsis thaliana Plants With Disturbed Pigment and Polyprenol Composition. Front Cell Dev Biol 8, 586628.

Cotton, F.A., Wilkinson, G., and Gaus, P.L. (1995). Basic Inorganic Chemistry. In lonic solids (Wiley), pp. 139.

Floris, D., and Kuhlbrandt, W. (2021). Molecular landscape of etioplast inner membranes in higher plants. Nat Plants 7, 514-523.

Fujii, S., Nagata, N., Masuda, T., Wada, H., and Kobayashi, K. (2019). Galactolipids Are Essential for Internal Membrane Transformation during Etioplast-to-Chloroplast Differentiation. Plant Cell Physiol 60, 1224-1238.

Gao, H., Sage, T.L., and Osteryoung, K.W. (2006). FZL, an FZO-like protein in plants, is a determinant of thylakoid and chloroplast morphology. Proceedings of the National Academy of Sciences of the United States of America 103, 6759 - 6764.

Grzyb, J.M., Solymosi, K., Strzalka, K., and Mysliwa-Kurdziel, B. (2013). Visualization and characterization of prolamellar bodies with atomic force microscopy. J Plant Physiol 170, 1217-1227.

Gunning, B.E.S. (1965). Greening Process in Plastids .1. Structure of Prolamellar Body. Protoplasma 60, 111-130.

Gunning, B.E.S. (2001). Membrane geometry of "open" prolamellar bodies. Protoplasma 215, 4-15.

Henningsen, K.W., and Boynton, J.E. (1974). Macromolecular physiology of plastids. IX. Development of plastid membranes during greening of dark-grown barley seedlings. J Cell Sci 15, 31-55.

Hernandez-Verdeja, T., Vuorijoki, L., and Strand, A. (2020). Emerging from the darkness: interplay between light and plastid signaling during chloroplast biogenesis. Physiol Plant 169, 397-406.

Hohmann-Marriott, M.F., Sousa, A.A., Azari, A.A., Glushakova, S., Zhang, G., Zimmerberg, J., and Leapman, R.D. (2009). Nanoscale 3D cellular imaging by axial scanning transmission electron tomography. Nature methods 6, 729 - 731.

Jarvis, P., and López-Juez, E. (2013). Biogenesis and homeostasis of chloroplasts and other plastids. Nature Reviews Molecular Cell Biology 14, 787-802.

Kang, B.-H. (2010). Electron Microscopy and High-Pressure Freezing of Arabidopsis. In Electron Microscopy of Model Systems, T. Müller-Reichert, ed, pp. 259-283.

Kang, B.-H. (2016). STEM Tomography Imaging of Hypertrophied Golgi Stacks in Mucilage-Secreting Cells. Methods in molecular biology (Clifton, N.J.) 1496, 55 - 62.

Kang, B.-H., Busse, J.S., and Bednarek, S.Y. (2003). Members of the Arabidopsis Dynamin-Like Gene Family, ADL1, Are Essential for Plant Cytokinesis and Polarized Cell Growth. The Plant Cell 15, $899-913$.

Kirchhoff, H. (2019). Chloroplast ultrastructure in plants. New Phytol 223, 565-574.

Kiss, A.Z., Giddings, T.H., Staehelin, L.A., and Sack, F.D. (1990). Comparison of the ultrastructure of conventionally fixed and high pressure frozen/freeze substituted root tips of Nicotiana and Arabidopsis Protoplasma 157, 64-74. 
bioRxiv preprint doi: https://doi.org/10.1101/2021.12.01.470752; this version posted December 1 , 2021. The copyright holder for this preprint (which was not certified by peer review) is the author/funder. All rights reserved. No reuse allowed without permission.

Kollmannsberger, P., Kerschnitzki, M., Repp, F., Wagermaier, W., Weinkamer, R., and Fratzl, P. (2017). The small world of osteocytes: connectomics of the lacuno-canalicular network in bone. New Journal of Physics 19, 073019.

Kowalewska, Ł., Mazur, R., Suski, S., Garstka, M., and Mostowska, A. (2016). Three-Dimensional Visualization of the Tubular-Lamellar Transformation of the Internal Plastid Membrane Network during Runner Bean Chloroplast Biogenesis. THE PLANT CELL ONLINE 28, 875 891.

Lee, K.-H., Park, J., Williams, D.S., Xiong, Y., Hwang, I., and Kang, B.-H. (2013). Defective chloroplast development inhibits maintenance of normal levels of abscisic acid in a mutant of the Arabidopsis RH3 DEAD-box protein during early post-germination growth. The Plant Journal 73, $720-732$.

Liang, Z., Zhu, N., Mai, K.K., Liu, Z., Liu, Z., Tzeng, D., Tzeng, D.T.W., Osteryoung, K.W., Zhong, S., Staehelin, L.A., Staehelin, A., and Kang, B.-H. (2018). Thylakoid-Bound Polysomes and a Dynamin-Related Protein, FZL, Mediate Critical Stages of the Linear Chloroplast Biogenesis Program in Greening Arabidopsis Cotyledons. THE PLANT CELL ONLINE 30, $1476-1495$.

Ma, J., Liang, Z., Zhao, J., Wang, P., Ma, W., Mai, K.K., Fernandez Andrade, J.A., Zeng, Y., Grujic, N., Jiang, L., Dagdas, Y., and Kang, B.H. (2021). Friendly mediates membrane depolarization-induced mitophagy in Arabidopsis. Current Biology 31, 1931-1944.

Mai, K.K.K., and Kang, B.-H. (2017). Semiautomatic Segmentation of Plant Golgi Stacks in Electron Tomograms Using 3dmod. Methods in molecular biology (Clifton, N.J.) 1662, 97 - 104.

Mai, K.K.K., Yeung, W.-T., Han, S.-Y., Cai, X., Hwang, I., and Kang, B.-H. (2019). Electron Tomography Analysis of Thylakoid Assembly and Fission in Chloroplasts of a Single-Cell C4 plant, Bienertia sinuspersici. Scientific Reports 9, 19640.

McIntosh, R., Nicastro, D., and Mastronarde, D. (2005). New views of cells in 3D: an introduction to electron tomography. Trends Cell Biol 15, 43-51.

Murakami, S., Yamada, N., Nagano, M., and Osumi, M. (1985). 3-Dimensional Structure of the Prolamellar Body in Squash Etioplasts. Protoplasma 128, 147-156.

Murata, K., Esaki, M., Ogura, T., Arai, S., Yamamoto, Y., and Tanaka, N. (2014). Whole-cell imaging of the budding yeast Saccharomyces cerevisiae by high-voltage scanning transmission electron tomography. Ultramicroscopy 146, $39-45$.

Nguyen, H.C., Melo, A.A., Kruk, J., Frost, A., and Gabruk, M. (2021). Photocatalytic LPOR forms helical lattices that shape membranes for chlorophyll synthesis. Nat Plants 7, 437-444.

Nicolas, W.J., Bayer, E., and Brocard, L. (2018). Electron Tomography to Study the Threedimensional Structure of Plasmodesmata in Plant Tissues-from High Pressure Freezing Preparation to Ultrathin Section Collection. Bio Protoc 8, e2681.

Otegui, M.S. (2021). High-Pressure Freezing and Freeze Substitution for Transmission Electron Microscopy Imaging and Immunogold-Labeling. Methods Mol Biol 2200, 337-347.

Otegui, M.S., and Staehelin, L.A. (2004). Electron tomographic analysis of post-meiotic cytokinesis during pollen development in Arabidopsis thaliana. Planta 218, 501-515.

Otegui, M.S., Mastronarde, D.N., Kang, B.H., Bednarek, S.Y., and Staehelin, L.A. (2001). Threedimensional analysis of syncytial-type cell plates during endosperm cellularization visualized by high resolution electron tomography. Plant Cell 13, 2033-2051.

Paddock, T., Lima, D., Mason, M.E., Apel, K., and Armstrong, G.A. (2012). Arabidopsis lightdependent protochlorophyllide oxidoreductase A (PORA) is essential for normal plant growth and development. Plant Mol Biol 78, 447-460.

Pipitone, R., Eicke, S., Pfister, B., Glauser, G., Falconet, D., Uwizeye, C., Pralon, T., Zeeman, S.C., Kessler, F., and Demarsy, E. (2021). A multifaceted analysis reveals two distinct phases of chloroplast biogenesis during de-etiolation in Arabidopsis. Elife $\mathbf{1 0 .}$

Ploscher, M., Reisinger, V., and Eichacker, L.A. (2011). Proteomic comparison of etioplast and chloroplast protein complexes. J Proteomics 74, 1256-1265.

Pribil, M., Labs, M., and Leister, D. (2014). Structure and dynamics of thylakoids in land plants. Journal of Experimental Botany 65, 1955 - 1972.

Rascio, N., Mariani, P., and Casadoro, G. (1984). Etioplast-Chloroplast Transformation in Maize Leaves - Effects of Tissue Age and Light-Intensity. Protoplasma 119, 110-120.

Ryberg, M., and Sundqvist, C. (1982). Characterization of Prolamellar Bodies and Prothylakoids Fractionated from Wheat Etioplasts. Physiologia Plantarum 56, 125-132.

Samuels, A.L., Giddings, T.H., Jr., and Staehelin, L.A. (1995). Cytokinesis in tobacco BY-2 and root tip cells: a new model of cell plate formation in higher plants. J Cell Biol 130, 1345-1357. 
bioRxiv preprint doi: https://doi.org/10.1101/2021.12.01.470752; this version posted December 1, 2021. The copyright holder for this preprint (which was not certified by peer review) is the author/funder. All rights reserved. No reuse allowed without permission.

Sandoval-lbanez, O., Sharma, A., Bykowski, M., Borras-Gas, G., Behrendorff, J., Mellor, S., Qvortrup, K., Verdonk, J.C., Bock, R., Kowalewska, L., and Pribil, M. (2021). Curvature thylakoid 1 proteins modulate prolamellar body morphology and promote organized thylakoid biogenesis in Arabidopsis thaliana. Proc Natl Acad Sci U S A 118.

Segui-Simarro, J.M., Austin, J.R., 2nd, White, E.A., and Staehelin, L.A. (2004). Electron tomographic analysis of somatic cell plate formation in meristematic cells of Arabidopsis preserved by high-pressure freezing. Plant Cell 16, 836-856.

Selstam, E., Schelin, J., Williams, W.P., and Brain, A.P. (2007). Structural organisation of prolamellar bodies (PLB) isolated from Zea mays. Parallel TEM, SAXS and absorption spectra measurements on samples subjected to freeze-thaw, reduced $\mathrm{pH}$ and high-salt perturbation. Biochim Biophys Acta 1768, 2235-2245.

Solymosi, K., and Schoefs, B. (2010). Etioplast and etio-chloroplast formation under natural conditions: the dark side of chlorophyll biosynthesis in angiosperms. Photosynth Res 105, 143-166.

Staehelin, L.A., and Kang, B.H. (2008). Nanoscale architecture of endoplasmic reticulum export sites and of Golgi membranes as determined by electron tomography. Plant Physiol 147, 1454-1468.

Wang, P., Chen, X., Goldbeck, C., Chung, E., and Kang, B.-H. (2017). A distinct class of vesicles derived from the trans-Golgi mediates secretion of xylogalacturonan in the root border cell. The Plant Journal 92, 596 - 610.

Williams, W.P., Selstam, E., and Brain, T. (1998). X-ray diffraction studies of the structural organisation of prolamellar bodies isolated from Zea mays. FEBS Lett 422, 252-254.

Zhang, S., Heyes, D.J., Feng, L., Sun, W., Johannissen, L.O., Liu, H., Levy, C.W., Li, X., Yang, J., Yu, X., Lin, M., Hardman, S.J.O., Hoeven, R., Sakuma, M., Hay, S., Leys, D., Rao, Z., Zhou, A., Cheng, Q., and Scrutton, N.S. (2019). Structural basis for enzymatic photocatalysis in chlorophyll biosynthesis. Nature 574, 722-725.

Zhang, X., Henriques, R., Lin, S.-S., Niu, Q.-W., and Chua, N.-H. (2006). Agrobacterium-mediated transformation of Arabidopsis thaliana using the floral dip method. Nature protocols 1, 641. 

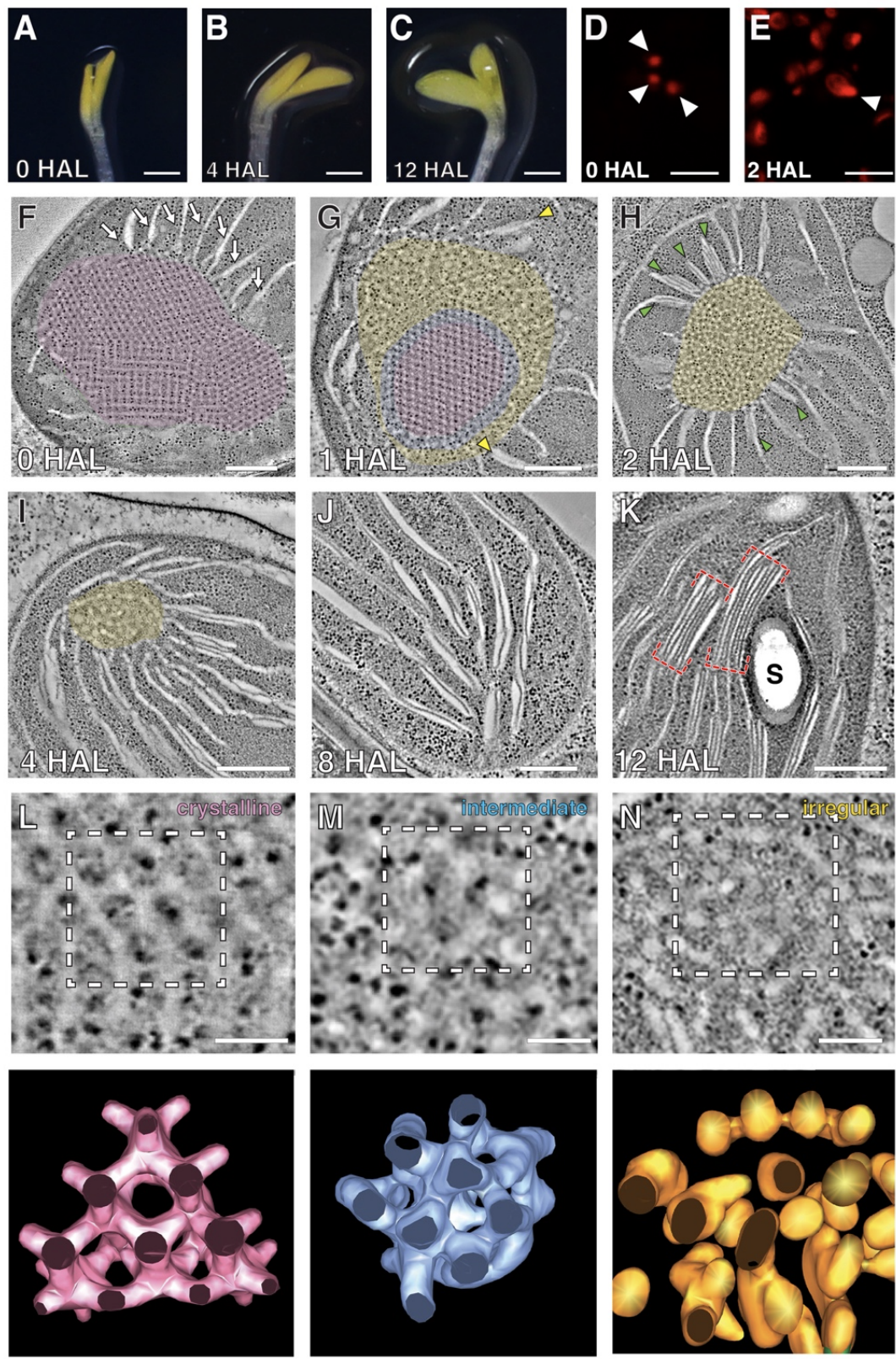

Figure 1. PLB degeneration and thylakoid assembly in de-etiolating Arabidopsis cotyledons. (AC) 7-day-old etiolated Arabidopsis cotyledons at $A) 0 \mathrm{HAL}, B) 4 \mathrm{HAL}$, and $C) 12 \mathrm{HAL}$. (D-E) Confocal laser scanning micrographs showing Pchlide/chlorophyll autofluorescence at $D) 0 \mathrm{HAL}$ and $E) 2 \mathrm{HAL}$. Arrowheads indicate PLBs. (F-K) STET slice images of plastids at $F$ ) $0 \mathrm{HAL}, G) 1 \mathrm{HAL}, H) 2 \mathrm{HAL}, I) 4$ $\mathrm{HAL}, \mathcal{J} 8 \mathrm{HAL}$, and $K) 12 \mathrm{HAL}$. The crystalline, irregular, and intermediate zones in PLBs are highlighted in magenta, yellow, and blue, respectively, in $(F)-(I)$. Yellow arrowheads in $(G)$ mark grana stacks of two layers. Green arrowheads in $(H)$ indicate PLB-associated grana stacks. Grana stacks in $(K)$ are denoted with red brackets. S: starch particle. Scale bars $=300 \mathrm{~nm}$. $(L-N)$ High magnification tomographic slice images of the PLB lattice (crystalline) at 0 HAL (L), PLB tubules of the intermediate zone at $1 \mathrm{HAL}(M)$, and PLB tubules of the irregular zone at $1 \mathrm{HAL}(N)$. Scale bars $=150 \mathrm{~nm}$. Lower panels show $3 \mathrm{D}$ surface models of the PLB membranes demarcated with dashed squares in upper images. 

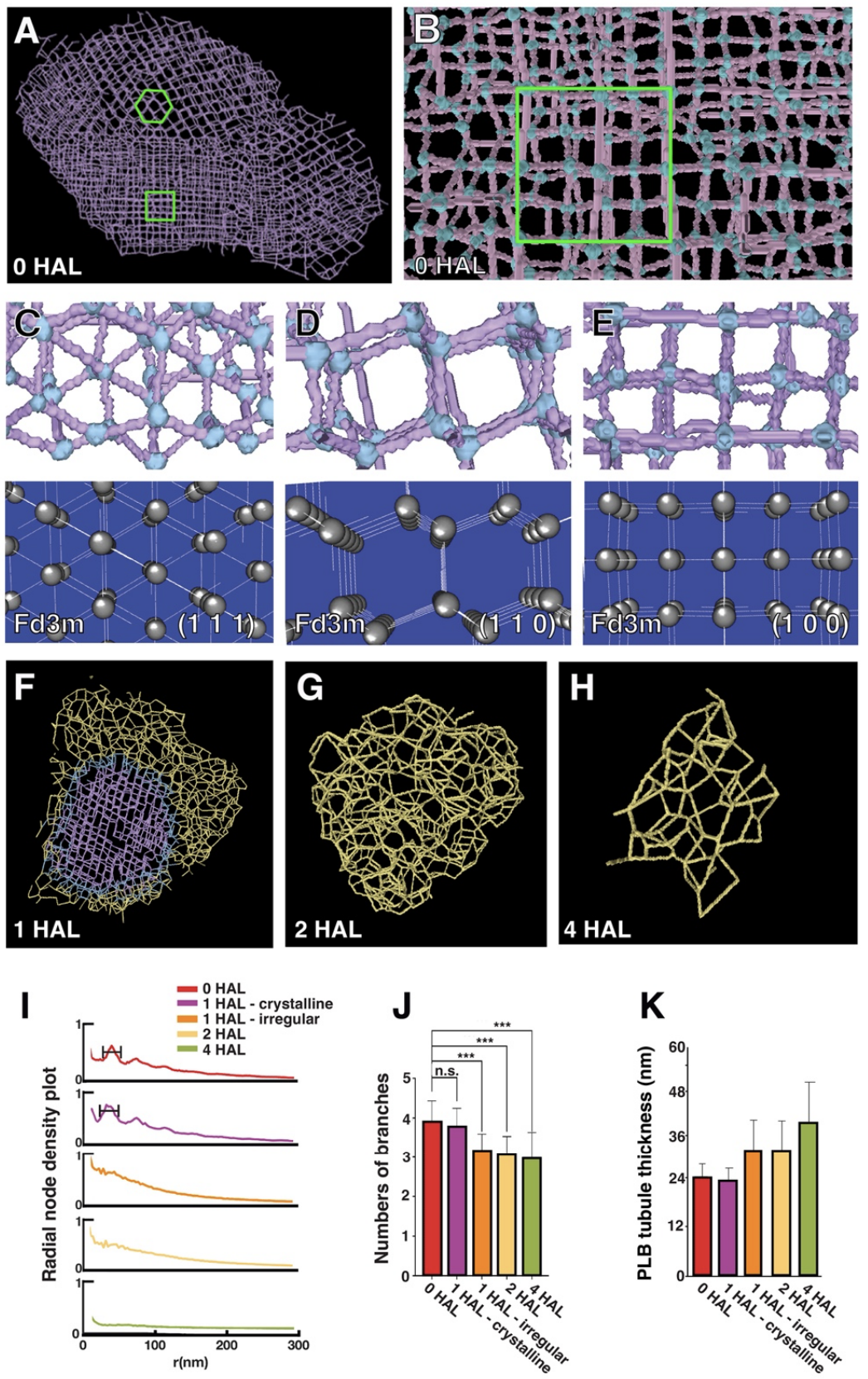

Figure 2. The crystalline structure of Arabidopsis PLB and its decay during de-etiolation. $(A) A$ skeleton model of the PLB in Fig. 1F. Regions exhibiting hexagonal or square lattice patterns are marked in green. (B) A higher magnification view of the skeleton model shown in panel A. Nodes are highlighted in light blue. The region exhibiting a square lattice pattern is marked in green. $(C-E)$ Projection views of select regions (upper panels), and lattice planes of the space group Fd3m (cubic diamond crystal structure) and their Miller indices, $(1,1,1),(1,1,0)$, and $(1,0,0)$ of the PLB skeleton model in panel B (bottom panels). Note that arrangements of PLB nodes and tubules match those of the cubic diamond lattices in all three planes. $(F-H)$ Skeleton models of decaying PLBs at $F$ ) $1 \mathrm{HAL}, G) 2 \mathrm{HAL}$, and $H) 4 \mathrm{HAL}$. The models were generated from the tomograms in Fig. $1 \mathrm{G}, \mathrm{H}$, and I, respectively. Lines are color-coded to denote the crystalline, irregular, and intermediate zones in PLBs. ( $/$ ) Radial density plots of branching nodes at four timepoints of de-etiolation. $(\mathcal{J})$ The average numbers of branches at each node in $0 \mathrm{HAL}, 1 \mathrm{HAL}$ crystalline, $1 \mathrm{HAL}$ irregular, $2 \mathrm{HAL}$, and $4 \mathrm{HAL}$ PLBs. $(K)$ The average diameters of tubules in $0 \mathrm{HAL}, 1 \mathrm{HAL}$ crystalline, $1 \mathrm{HAL}$ irregular, $2 \mathrm{HAL}$, and $4 \mathrm{HAL}$ PLBs. 


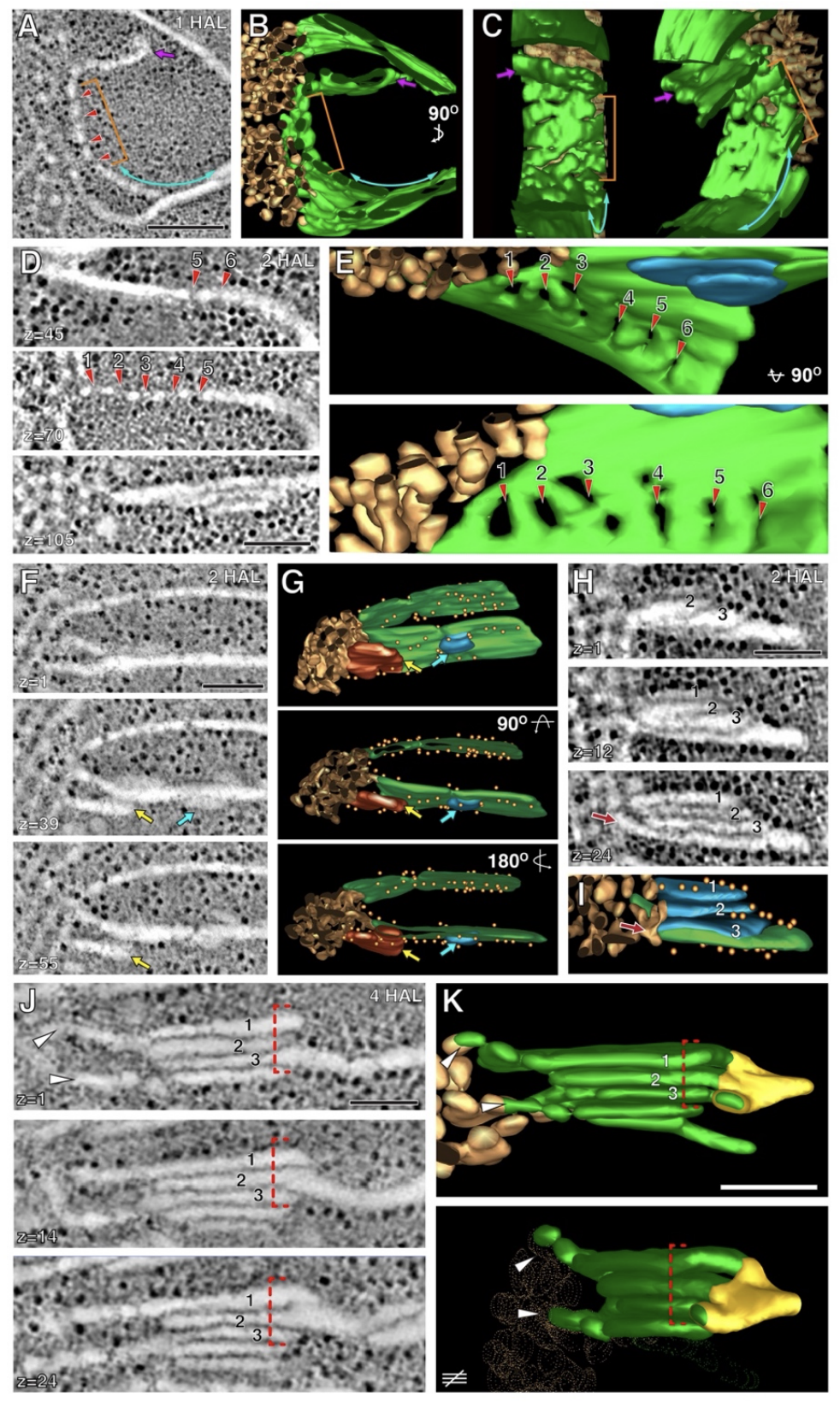

Figure 3. PLB to pre-granal thylakoid transition and grana formation from pre-granal thylakoids $(A-E)$ Tomographic slice images (panels $A$ and $D$ ) and $3 D$ models of fenestrated sheets on the PLBs at $1 \mathrm{HAL}$. The membrane in panels $D-E$ is more consolidated than the sheet shown in panel A. Holes indicated by the red arrowheads. $(F-G)$ High-magnification images of two pre-granal thylakoids connected to PLB periphery and their 3D models. Buds on pre-granal thylakoids are indicated by blue arrows. Connections with nascent pre-granal thylakoid are indicated by yellow arrows. $(H-I)$ Image and 3D model of a grana-forming stack consisting of four layers at the margin of a decaying PLB. Three small lamellae (blue) derived from the irregular PLB margin are on a grana-forming thylakoid (green). They are interconnected via their edges. $(J-K)$ Images and 3D model of a grana-stroma thylakoid that appears more mature than the grana-forming stack in panels $\mathrm{F}-\mathrm{H}$. The grana layers are connected to each other through membrane folds (red brackets). The model in the lower panel is a view after $90^{\circ}$ rotation. The helical arranged stroma thylakoids (yellow) interconnected the new grana stack. Scale bars $=100 \mathrm{~nm}$. 

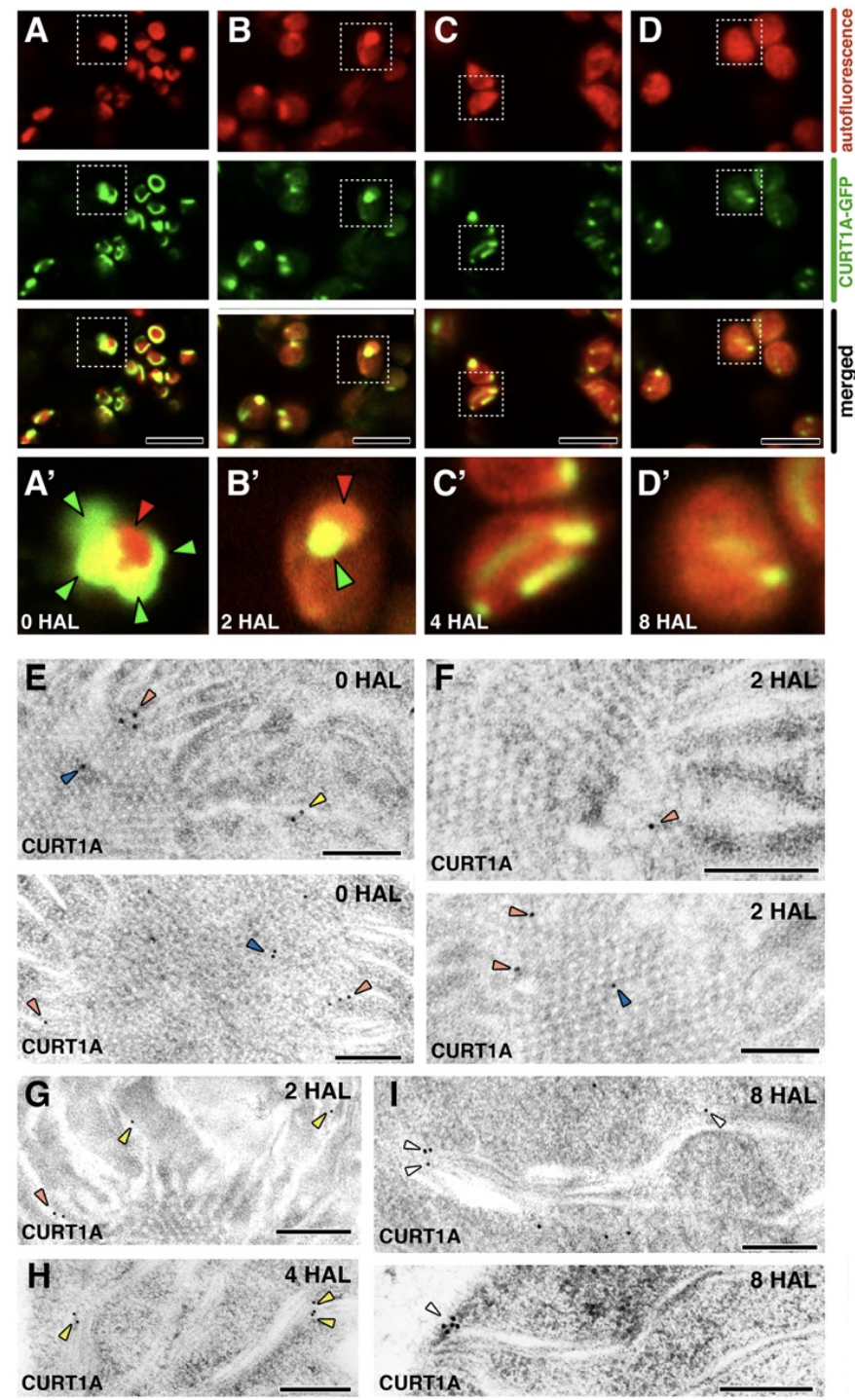

J

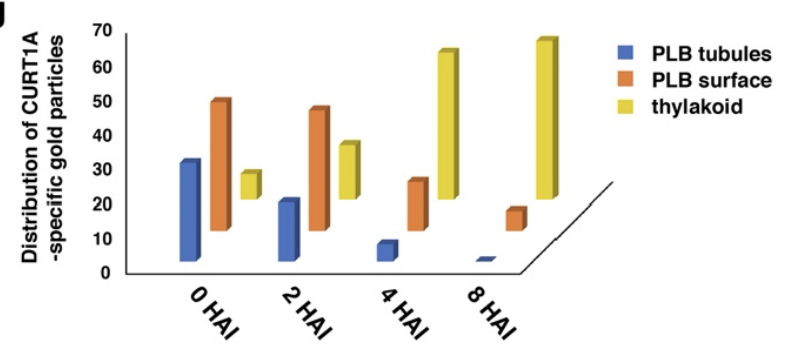

Figure 4. Localization of CURT1A proteins during de-etiolation. (A-D) Confocal laser scanning micrographs showing CURT1A-GFP distribution at A) $0 \mathrm{HAL}$, B) $2 \mathrm{HAL}, \mathrm{C)} 4 \mathrm{HAL}$, and D) $8 \mathrm{HAL}$. Autofluorescence from Pchlide/chlorophyll, fluorescence from CURT1A-GFP, and merged panels are shown in each column. Panels $A^{\prime}-D^{\prime}$ are high-magnification micrographs of regions indicated with squares in panels A-D. In A' and B', PLBs and CURT1A-GFP puncta are indicated with red and green arrowheads. Scale bars $=8 \mu \mathrm{m}$. $(E-l)$ Immunogold labeling localization of CURT1A in Arabidopsis plastids at E) $0 \mathrm{HAL}, \mathrm{F}) 1 \mathrm{HAL}, \mathrm{G}) 2 \mathrm{HAL}, \mathrm{H}) 4 \mathrm{HAL}$, and I) $8 \mathrm{HAL}$. Gold particles located in PLBs, periphery of PLBs, and thylakoids are marked with blue, orange and yellow arrowheads, respectively. Scale bars $=200 \mathrm{~nm}$. $(J)$ Histogram showing CURT1A-specific gold particle distribution in Arabidopsis plastids at $0 \mathrm{HAL}, 1 \mathrm{HAL}, 2 \mathrm{HAL}$, and $4 \mathrm{HAL}$. 


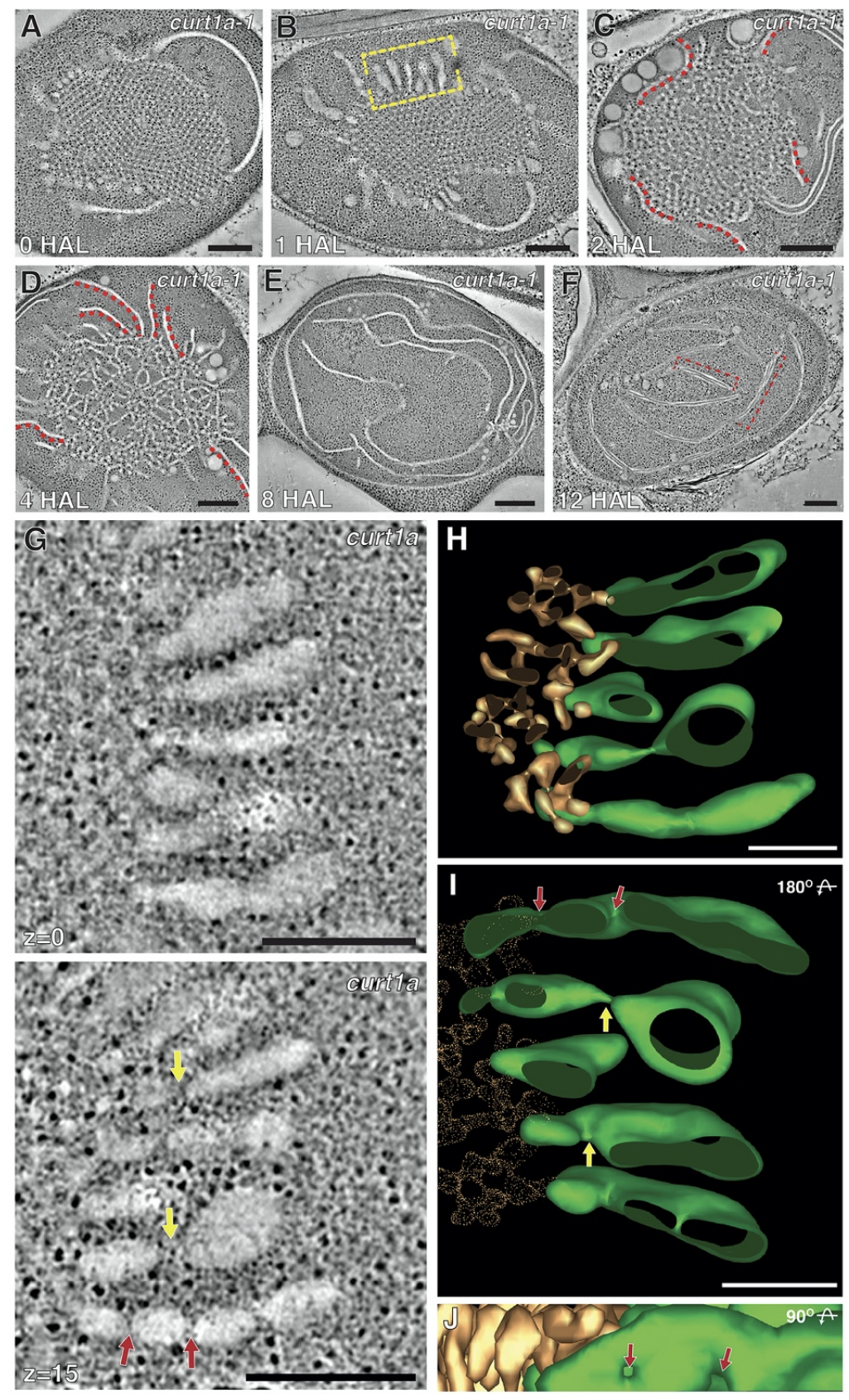

Figure 5. Plastid de-etiolation is altered in the curt1a mutant. ( $A-F$ ) STEM tomography slices of curt1a-1 plastids at A) $0 \mathrm{HAL}, B) 1 \mathrm{HAL}, \mathrm{C)} 2 \mathrm{HAL}, \mathrm{D}) 4 \mathrm{HAL}$, E) $8 \mathrm{HAL}$, and F) $12 \mathrm{HAL}$. Red dots in (C) and $(D)$ label pre-granal thylakoids associated with PLBs but no grana stacks arise from them. Scale bars $=300 \mathrm{~nm}$. (G) A tomographic slice image of the thylakoids connected to PLBs in the yellow bracket in panel B. Fenestrations in pre-granal thylakoids are indicated by red and yellow arrows. Scale bars = $200 \mathrm{~nm}$. (H-J) 3D model of the image in panel G with thylakoids in green and PLBs in gold. The 3D model in panel $\mathrm{I}$ is rotated $180^{\circ}$ relative to that in panel $\mathrm{H}$ and that in panel $\mathrm{J}$ is rotated an additional $90^{\circ}$. Fenestrations are indicated by yellow and red arrows. Scale bars $=100 \mathrm{~nm}$. 

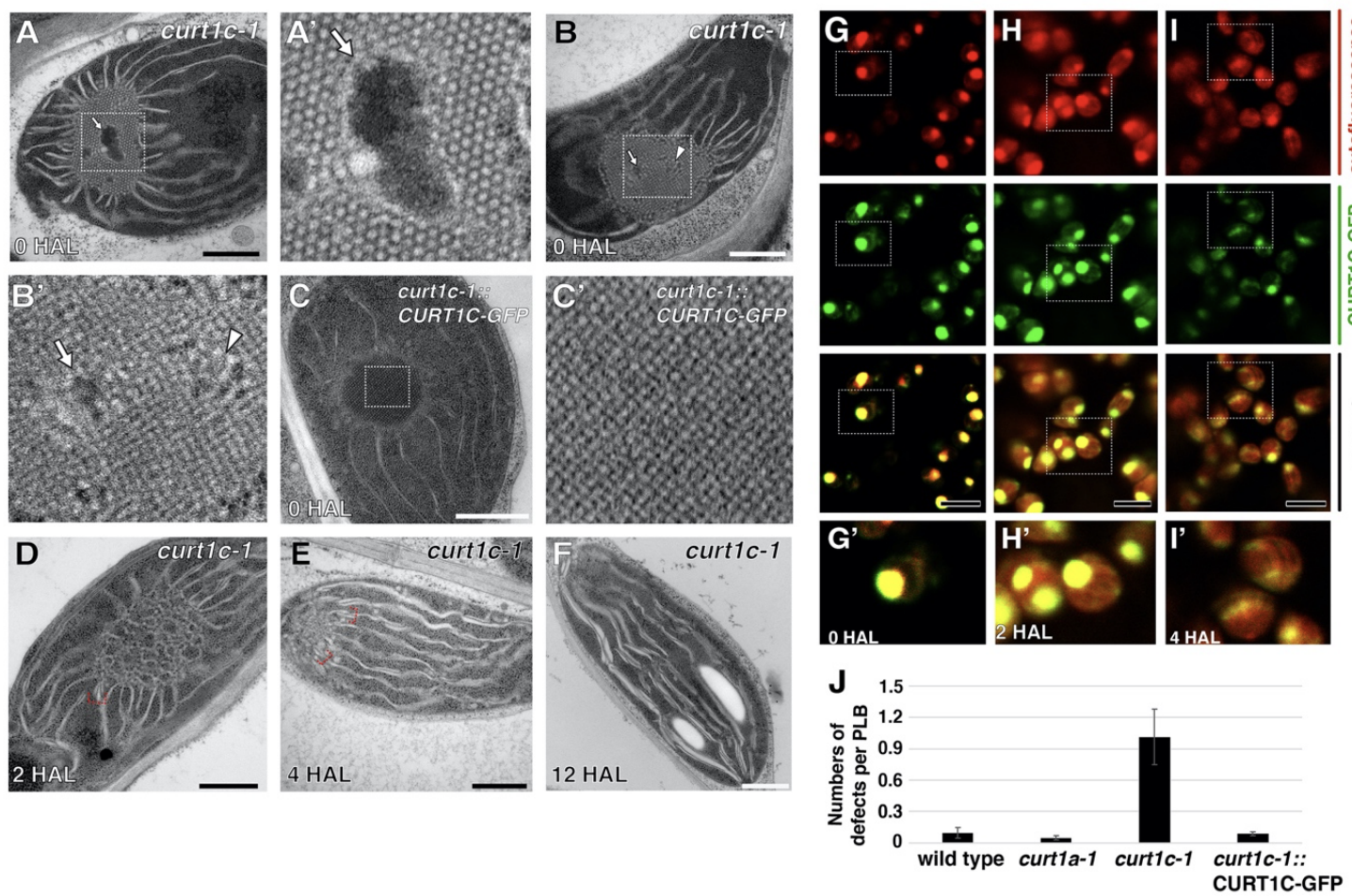

Figure 6. PLBs in curt1c mutant etioplasts are abnormal. (A-B) TEM micrographs of PLBs in curt1c1 etioplasts at $0 \mathrm{HAL}$. Holes and disordred tubules are marked with arrows and arrowheads, respectively. (C) TEM micrograph of an etioplast in curt1c-1 expressing CURT1C-GFP at 0 HAL. A'-C' are magnified views of PLBs inside the rectangles in panels A-C. (D-F) TEM micrographs of curt1c-1 plastids at D) $2 \mathrm{HAL}$, E) $4 \mathrm{HAL}$, and F) $12 \mathrm{HAL}$. Grana stacks associated with PLBs are denoted with brackets in panels $\mathrm{D}$ and $\mathrm{E}$. $(\mathrm{G}-\mathrm{H})$ Confocal laser scanning micrographs showing CURT1C-GFP distribution at G) $0 \mathrm{HAL}, \mathrm{H}) 2 \mathrm{HAL}$, and I) $4 \mathrm{HAL}$. Autofluorescence from Pchlide/chlorophyll, fluorescence from CURT1C-GFP, and merged panels are shown in each column. Panels G'-l' are highmagnification micrographs of regions denoted with squares in panels G-I. $(J)$ Frequencies of PLB irregularities. The histogram was produced after analyzing $\sim 30$ etioplasts from at least three samples for each genotype. Most PLBs had pores or abnormal tubules in curt1c-1. 
A

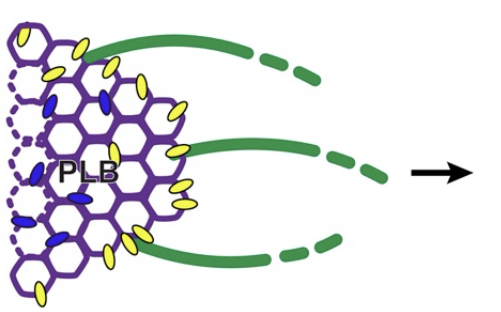

under darkness

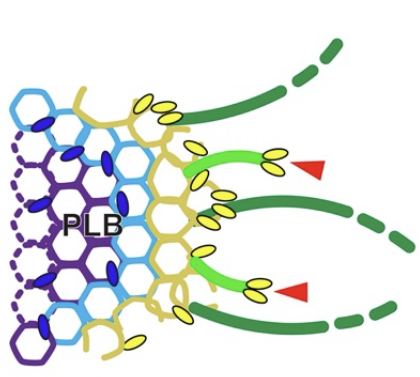

WT, 1 hr illumination

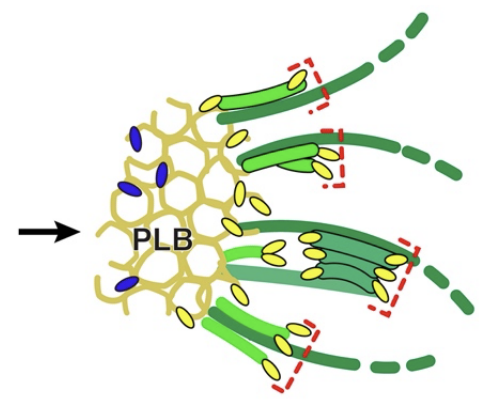

WT, 2-4hr illumination

CURT1A
CURT1C

B

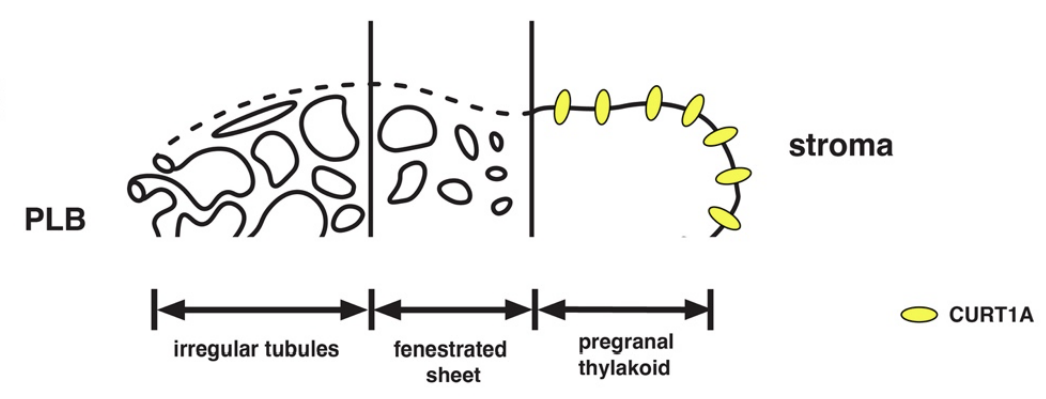

C

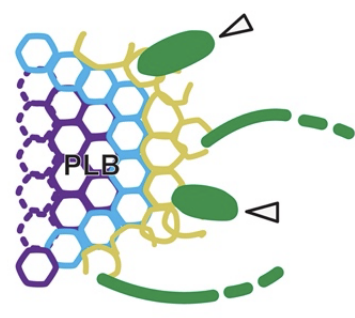

curt1a, $1 \mathrm{hr}$ illumination

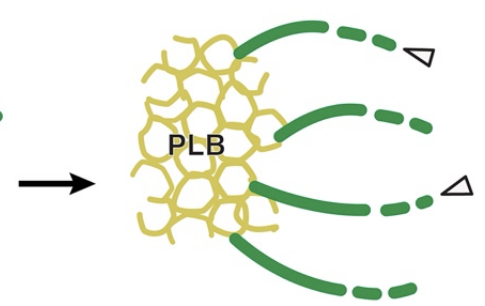

curt1a, 2-4 hr illumination

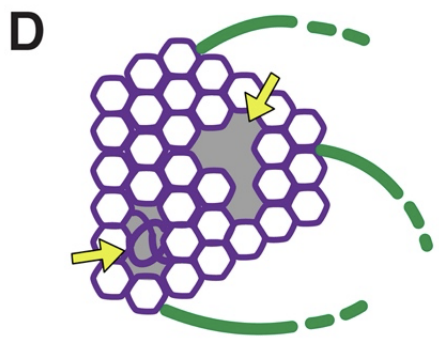

PLB in the curt1c etioplast

Figure 7. Schematic diagrams illustrating functions of CURT1A and CURT1C during deetiolation. ( $A$ ) Both CURT1A and CURT1C are localized in PLBs. Upon illumination, PLB decay occurs from the margin, and CURT1A concentrates to the sites where new pre-granal thylakoids emerge (arrowheads) and grana stacks arise (brackets). CURT1C does not exhibit such relocation dynamics. (B) Model of pre-granal thylakoid development from PLB tubules. The irregular region of degrading PLBs resemble a tubule-vesicular meshwork that gradually coalesces into a fenestrated sheet. CURT1A bends the membrane at the edge of a nascent pre-granal thylakoid outgrowing from a PLB into the stroma. (C) Pre-granal thylakoids growing out from PLBs in curt1a are swollen (arrowheads) and they elongate without creating grana stacks. (D) PLBs lacking CURT1C have pores and disorganized tubules (arrows). 


\section{Parsed Citations}

Ahn, G., Kim, H., Kim, D.H., Hanh, N.H., Yoon, Y., Singaram, I., Wijesinghe, K.J., Johnson, K.A, Zhuang, X.-H., Liang, Z, Stahelin, R.V., Jiang, L., Cho, W., Kang, B.-H., and Hwang, I. (2017). SH3P2 plays a crucial role at the step of membrane tubulation during cell plate formation in plants. THE PLANT CELL ONLINE 29, 1388 - 1405.

Google Scholar: Author Only Title Only Author and Title

Aoyama, K., Takagi, T., Hirase, A, and Miyazawa, A (2008). STEM tomography for thick biological specimens. Ultramicroscopy 109, 7080.

Google Scholar: Author Only Title Only Author and Title

Armarego-Marriott, T., Kowalewska, L., Burgos, A, Fischer, A, Thiele, W., Erban, A, Strand, D., Kahlau, S., Hertle, A, Kopka, J., Walther, D., Reich, Z, Schottler, M.A, and Bock, R. (2019). Highly Resolved Systems Biology to Dissect the Etioplast-to-Chloroplast Transition in Tobacco Leaves. Plant Physiol 180, 654-681.

Google Scholar: Author Only Title Only Author and Title

Armbruster, U., Labs, M., Pribil, M., Viola, S., Xu, W., Scharfenberg, M., Hertle, AP., Rojahn, U., Jensen, P.E., Rappaport, F., Joliot, P., Dörmann, P., Wanner, G., and Leister, D. (2013). Arabidopsis CURVATURE THYLAKOID1 proteins modify thylakoid architecture by inducing membrane curvature. THE PLANT CELL ONLINE 25, 2661 - 2678.

Google Scholar: Author Only Title Only Author and Title

Blomqvist, L.A, Ryberg, M., and Sundqvist, C. (2008). Proteomic analysis of highly purified prolamellar bodies reveals their significance in chloroplast development. Photosynthesis Research 96, 37-50.

Google Scholar: Author Only Title Only Author and Title

Bykowski, M., Mazur, R., Buszewicz, D., Szach, J., Mostowska, A, and Kowalewska, L. (2020). Spatial Nano-Morphology of the Prolamellar Body in Etiolated Arabidopsis thaliana Plants With Disturbed Pigment and Polyprenol Composition. Front Cell Dev Biol 8, 586628.

Google Scholar: Author Only Title Only Author and Title

Cotton, F.A, Wilkinson, G., and Gaus, P.L. (1995). Basic Inorganic Chemistry. In lonic solids (Wiley), pp. 139.

Google Scholar: Author Only Title Only Author and Title

Floris, D., and Kuhlbrandt, W. (2021). Molecular landscape of etioplast inner membranes in higher plants. Nat Plants 7, 514-523.

Google Scholar: Author Only Title Only Author and Title

Fujii, S., Nagata, N., Masuda, T., Wada, H., and Kobayashi, K. (2019). Galactolipids Are Essential for Internal Membrane Transformation during Etioplast-to-Chloroplast Differentiation. Plant Cell Physiol 60, 1224-1238.

Google Scholar: Author Only Title Only Author and Title

Gao, H., Sage, T.L., and Osteryoung, K.W. (2006). FZ, an FZO-like protein in plants, is a determinant of thylakoid and chloroplast morphology. Proceedings of the National Academy of Sciences of the United States of America 103, 6759 - 6764.

Google Scholar: Author Only Title Only Author and Title

Grzyb, J.M., Solymosi, K., Strzalka, K., and Mysliwa-Kurdziel, B. (2013). Visualization and characterization of prolamellar bodies with atomic force microscopy. J Plant Physiol 170, 1217-1227.

Google Scholar: Author Only Title Only Author and Title

Gunning, B.E.S. (1965). Greening Process in Plastids .1. Structure of Prolamellar Body. Protoplasma 60, 111-130.

Google Scholar: Author Only Title Only Author and Title

Gunning, B.E.S. (2001). Membrane geometry of "open" prolamellar bodies. Protoplasma 215, 4-15.

Google Scholar: Author Only Title Only Author and Title

Henningsen, K.W., and Boynton, J.E. (1974). Macromolecular physiology of plastids. IX. Development of plastid membranes during greening of dark-grown barley seedlings. J Cell Sci 15, 31-55.

Google Scholar: Author Only Title Only Author and Title

Hernandez-Verdeja, T., Vuorijoki, L., and Strand, A (2020). Emerging from the darkness: interplay between light and plastid signaling during chloroplast biogenesis. Physiol Plant 169, 397-406.

Google Scholar: Author Only Title Only Author and Title

Hohmann-Marriott, M.F., Sousa, AA, Azari, AA, Glushakova, S., Zhang, G., Zmmerberg, J., and Leapman, R.D. (2009). Nanoscale 3D cellular imaging by axial scanning transmission electron tomography. Nature methods 6, 729 - 731.

Google Scholar: Author Only Title Only Author and Title

Jarvis, P., and López-Juez, E. (2013). Biogenesis and homeostasis of chloroplasts and other plastids. Nature Reviews Molecular Cell Biology 14, 787-802.

Google Scholar: Author Only Title Only Author and Title

Kang, B.-H. (2010). Electron Microscopy and High-Pressure Freezing of Arabidopsis. In Electron Microscopy of Model Systems, T. Müller-Reichert, ed, pp. 259-283.

Google Scholar: Author Only Title Only Author and Title 
Kang, B.-H. (2016). STEM Tomography Imaging of Hypertrophied Golgi Stacks in Mucilage-Secreting Cells. Methods in molecular biology (Clifton, N.J.) 1496, 55 - 62.

Google Scholar: Author Only Title Only Author and Title

Kang, B.-H., Busse, J.S., and Bednarek, S.Y. (2003). Members of the Arabidopsis Dynamin-Like Gene Family, ADL1, Are Essential for

Plant Cytokinesis and Polarized Cell Growth. The Plant Cell 15, 899 - 913.

Google Scholar: Author Only Title Only Author and Title

Kirchhoff, H. (2019). Chloroplast ultrastructure in plants. New Phytol 223, 565-574.

Google Scholar: Author Only Title Only Author and Title

Kiss, AZ, Giddings, T.H., Staehelin, L.A, and Sack, F.D. (1990). Comparison of the ultrastructure of conventionally fixed and high pressure frozen/freeze substituted root tips of Nicotiana and Arabidopsis Protoplasma 157, 64-74.

Google Scholar: Author Only Title Only Author and Title

Kollmannsberger, P., Kerschnitzki, M., Repp, F., Wagermaier, W., Weinkamer, R., and Fratzl, P. (2017). The small world of osteocytes: connectomics of the lacuno-canalicular network in bone. New Journal of Physics 19, 073019.

Google Scholar: Author Only Title Only Author and Title

Kowalewska, Ł., Mazur, R., Suski, S., Garstka, M., and Mostowska, A (2016). Three-Dimensional Visualization of the Tubular-Lamellar Transformation of the Internal Plastid Membrane Network during Runner Bean Chloroplast Biogenesis. THE PLANT CELL ONLINE 28, 875 - 891.

Google Scholar: Author Only Title Only Author and Title

Lee, K.-H., Park, J., Williams, D.S., Xiong, Y., Hwang, I., and Kang, B.-H. (2013). Defective chloroplast development inhibits maintenance of normal levels of abscisic acid in a mutant of the Arabidopsis RH3 DEAD-box protein during early post-germination growth. The Plant Journal 73, 720 - 732.

Google Scholar: Author Only Title Only Author and Title

Liang, Z, Zhu, N., Mai, K.K., Liu, Z, Liu, Z, Tzeng, D., Tzeng, D.T.W., Osteryoung, K.W., Zhong, S., Staehelin, L.A, Staehelin, A, and Kang, B.-H. (2018). Thylakoid-Bound Polysomes and a Dynamin-Related Protein, FZ, Mediate Critical Stages of the Linear Chloroplast Biogenesis Program in Greening Arabidopsis Cotyledons. THE PLANT CELL ONLINE 30, 1476 - 1495.

Google Scholar: Author Only Title Only Author and Title

Ma, J., Liang, Z, Zhao, J., Wang, P., Ma, W., Mai, K.K., Fernandez Andrade, J.A, Zeng, Y., Grujic, N., Jiang, L., Dagdas, Y., and Kang, B.H. (2021). Friendly mediates membrane depolarization-induced mitophagy in Arabidopsis. Current Biology 31, $1931-1944$.

Google Scholar: Author Only Title Only Author and Title

Mai, K.K.K., and Kang, B.-H. (2017). Semiautomatic Segmentation of Plant Golgi Stacks in Electron Tomograms Using 3dmod. Methods in molecular biology (Clifton, N.J.) 1662, 97 - 104.

Google Scholar: Author Only Title Only Author and Title

Mai, K.K.K., Yeung, W.-T., Han, S.-Y., Cai, X., Hwang, I., and Kang, B.-H. (2019). Electron Tomography Analysis of Thylakoid Assembly and Fission in Chloroplasts of a Single-Cell C4 plant, Bienertia sinuspersici. Scientific Reports 9, 19640.

Google Scholar: Author Only Title Only Author and Title

McIntosh, R., Nicastro, D., and Mastronarde, D. (2005). New views of cells in 3D: an introduction to electron tomography. Trends Cell Biol 15, 43-51.

Google Scholar: Author Only Title Only Author and Title

Murakami, S., Yamada, N., Nagano, M., and Osumi, M. (1985). 3-Dimensional Structure of the Prolamellar Body in Squash Etioplasts.

Protoplasma 128, 147-156.

Google Scholar: Author Only Title Only Author and Title

Murata, K., Esaki, M., Ogura, T., Arai, S., Yamamoto, Y., and Tanaka, N. (2014). Whole-cell imaging of the budding yeast Saccharomyces cerevisiae by high-voltage scanning transmission electron tomography. Ultramicroscopy 146, 39 - 45.

Google Scholar: Author Only Title Only Author and Title

Nguyen, H.C., Melo, AA, Kruk, J., Frost, A, and Gabruk, M. (2021). Photocatalytic LPOR forms helical lattices that shape membranes for chlorophyll synthesis. Nat Plants 7, 437-444.

Google Scholar: Author Only Title Only Author and Title

Nicolas, W.J., Bayer, E., and Brocard, L. (2018). Electron Tomography to Study the Three-dimensional Structure of Plasmodesmata in Plant Tissues-from High Pressure Freezing Preparation to Ultrathin Section Collection. Bio Protoc 8, e2681.

Google Scholar: Author Only Title Only Author and Title

Otegui, M.S. (2021). High-Pressure Freezing and Freeze Substitution for Transmission Electron Microscopy Imaging and ImmunogoldLabeling. Methods Mol Biol 2200, 337-347.

Google Scholar: Author Only Title Only Author and Title

Otegui, M.S., and Staehelin, L.A (2004). Electron tomographic analysis of post-meiotic cytokinesis during pollen development in Arabidopsis thaliana. Planta 218, 501-515.

Google Scholar: Author Only Title Only Author and Title 
Otegui, M.S., Mastronarde, D.N., Kang, B.H., Bednarek, S.Y., and Staehelin, L.A (2001). Three-dimensional analysis of syncytial-type cell plates during endosperm cellularization visualized by high resolution electron tomography. Plant Cell 13, $2033-2051$.

Google Scholar: Author Only Title Only Author and Title

Paddock, T., Lima, D., Mason, M.E., Apel, K., and Armstrong, G.A (2012). Arabidopsis light-dependent protochlorophyllide oxidoreductase A(PORA) is essential for normal plant growth and development. Plant Mol Biol 78, 447-460.

Google Scholar: Author Only Title Only Author and Title

Pipitone, R., Eicke, S., Pfister, B., Glauser, G., Falconet, D., Uwizeye, C., Pralon, T., Zeeman, S.C., Kessler, F., and Demarsy, E. (2021). A multifaceted analysis reveals two distinct phases of chloroplast biogenesis during de-etiolation in Arabidopsis. Elife 10.

Google Scholar: Author Only Title Only Author and Title

Ploscher, M., Reisinger, V., and Eichacker, L.A (2011). Proteomic comparison of etioplast and chloroplast protein complexes. J Proteomics 74, 1256-1265.

Google Scholar: Author Only Title Only Author and Title

Pribil, M., Labs, M., and Leister, D. (2014). Structure and dynamics of thylakoids in land plants. Journal of Experimental Botany 65 , 1955 - 1972.

Google Scholar: Author Only Title Only Author and Title

Rascio, N., Mariani, P., and Casadoro, G. (1984). Etioplast-Chloroplast Transformation in Maize Leaves - Effects of Tissue Age and Light-Intensity. Protoplasma 119, 110-120.

Google Scholar: Author Only Title Only Author and Title

Ryberg, M., and Sundqvist, C. (1982). Characterization of Prolamellar Bodies and Prothylakoids Fractionated from Wheat Etioplasts. Physiologia Plantarum 56, 125-132.

Google Scholar: Author Only Title Only Author and Title

Samuels, AL., Giddings, T.H., Jr., and Staehelin, L.A (1995). Cytokinesis in tobacco BY-2 and root tip cells: a new model of cell plate formation in higher plants. J Cell Biol 130, 1345-1357.

Google Scholar: Author Only Title Only Author and Title

Sandoval-lbanez, O., Sharma, A, Bykowski, M., Borras-Gas, G., Behrendorff, J., Mellor, S., Qvortrup, K., Verdonk, J.C., Bock, R., Kowalewska, L., and Pribil, M. (2021). Curvature thylakoid 1 proteins modulate prolamellar body morphology and promote organized thylakoid biogenesis in Arabidopsis thaliana. Proc Natl Acad Sci U S A118.

Google Scholar: Author Only Title Only Author and Title

Segui-Simarro, J.M., Austin, J.R., 2nd, White, E.A, and Staehelin, L.A (2004). Electron tomographic analysis of somatic cell plate formation in meristematic cells of Arabidopsis preserved by high-pressure freezing. Plant Cell 16, 836-856.

Google Scholar: Author Only Title Only Author and Title

Selstam, E., Schelin, J., Williams, W.P., and Brain, AP. (2007). Structural organisation of prolamellar bodies (PLB) isolated from Zea mays. Parallel TEM, SAXS and absorption spectra measurements on samples subjected to freeze-thaw, reduced pH and high-salt perturbation. Biochim Biophys Acta 1768, 2235-2245.

Google Scholar: Author Only Title Only Author and Title

Solymosi, K., and Schoefs, B. (2010). Etioplast and etio-chloroplast formation under natural conditions: the dark side of chlorophyll biosynthesis in angiosperms. Photosynth Res 105, 143-166.

Google Scholar: Author Only Title Only Author and Title

Staehelin, L.A, and Kang, B.H. (2008). Nanoscale architecture of endoplasmic reticulum export sites and of Golgi membranes as determined by electron tomography. Plant Physiol 147, 1454-1468.

Google Scholar: Author Only Title Only Author and Title

Wang, P., Chen, X., Goldbeck, C., Chung, E., and Kang, B.-H. (2017). Adistinct class of vesicles derived from the trans-Golgi mediates secretion of xylogalacturonan in the root border cell. The Plant Journal 92, 596 - 610.

Google Scholar: Author Only Title Only Author and Title

Williams, W.P., Selstam, E., and Brain, T. (1998). X-ray diffraction studies of the structural organisation of prolamellar bodies isolated from Zea mays. FEBS Lett 422, 252-254.

Google Scholar: Author Only Title Only Author and Title

Zhang, S., Heyes, D.J., Feng, L., Sun, W., Johannissen, L.O., Liu, H., Levy, C.W., Li, X., Yang, J., Yu, X., Lin, M., Hardman, S.J.O., Hoeven, R., Sakuma, M., Hay, S., Leys, D., Rao, Z, Zhou, A, Cheng, Q., and Scrutton, N.S. (2019). Structural basis for enzymatic photocatalysis in chlorophyll biosynthesis. Nature 574, 722-725.

Google Scholar: Author Only Title Only Author and Title

Zhang, X., Henriques, R., Lin, S.-S., Niu, Q.-W., and Chua, N.-H. (2006). Agrobacterium-mediated transformation of Arabidopsis thaliana using the floral dip method. Nature protocols 1, 641.

Google Scholar: Author Only Title Only Author and Title 